\title{
A role for RNA post-transcriptional regulation in satellite cell activation
}

\author{
Nicholas H Farina', Melissa Hausburg², Nicole Dalla Betta', Crystal Pulliam, Deepak Srivastava², \\ DDW Cornelison ${ }^{4^{*}}$ and Bradley B Olwin ${ }^{1^{*}}$
}

\begin{abstract}
Background: Satellite cells are resident skeletal muscle stem cells responsible for muscle maintenance and repair. In resting muscle, satellite cells are maintained in a quiescent state. Satellite cell activation induces the myogenic commitment factor, MyoD, and cell cycle entry to facilitate transition to a population of proliferating myoblasts that eventually exit the cycle and regenerate muscle tissue. The molecular mechanism involved in the transition of a quiescent satellite cell to a transit-amplifying myoblast is poorly understood.

Methods: Satellite cells isolated by FACS from uninjured skeletal muscle and $12 \mathrm{~h}$ post-muscle injury from wild type and Syndecan-4 null mice were probed using Affymetrix 430v2 gene chips and analyzed by Spotfire ${ }^{\mathrm{tm}}$ and Ingenuity Pathway analysis to identify gene expression changes and networks associated with satellite cell activation, respectively. Additional analyses of target genes identify miRNAs exhibiting dynamic changes in expression during satellite cell activation. The function of the miRNAs was assessed using miRIDIAN hairpin inhibitors.
\end{abstract}

Results: An unbiased gene expression screen identified over 4,000 genes differentially expressed in satellite cells in vivo within $12 \mathrm{~h}$ following muscle damage and more than $50 \%$ of these decrease dramatically. RNA binding proteins and genes involved in post-transcriptional regulation were significantly over-represented whereas splicing factors were preferentially downregulated and mRNA stability genes preferentially upregulated. Furthermore, six computationally identified miRNAs demonstrated novel expression through muscle regeneration and in satellite cells. Three of the six miRNAs were found to regulate satellite cell fate.

Conclusions: The quiescent satellite cell is actively maintained in a state poised to activate in response to external signals. Satellite cell activation appears to be regulated by post-transcriptional gene regulation.

Keywords: Satellite cell, RNA post-transcriptional regulation, microRNA.

\section{Background}

Skeletal muscle is terminally differentiated and thus, requires a population of resident adult stem cells, satellite cells, for maintenance and repair [1-3]. Satellite cells are typically mitotically quiescent in resting muscle and activate to prepare for cell cycle entry by HGF $[4,5]$, nitric oxide [6], and TNF $\alpha$ [7], upon a muscle injury. Intracellular p38 $\alpha / \beta$ MAPK and downstream signaling is stimulated upon satellite cell activation, permitting MyoD induction (Troy et al. $)^{\mathrm{a}}$ [8], S-

\footnotetext{
*Correspondence: cornelisond@missouri.edu; bradley.olwin@colorado.edu ${ }^{4}$ Biological Sciences and Bond Life Sciences Center, University of Missouri, Columbia, MO 65211, USA

'Department of Molecular, Cellular, and Developmental Biology, University of Colorado, Boulder, CO 80309, USA

Full list of author information is available at the end of the article
}

phase entry [8,9], and subsequent proliferation. A subset of satellite cells self-renew to maintain the satellite cell pool $(\text { Troy et al.) })^{\mathrm{a}}[10,11]$ and generate a rapidly proliferating transit-amplifying myoblast population (Troy et al.) $)^{\mathrm{a}}[10]$.

The transition from a quiescent satellite cell to a proliferating, transit amplifying myoblast was thought to require extensive transcriptional induction as quiescent satellite cells have a low ratio of cytoplasmic volume to nuclear volume, few cellular organelles, tightly packed heterochromatin, and are believed to be metabolically inactive $[12,13]$. However, recent evidence suggests that satellite cell quiescence is 'active' and satellite cells are poised to react to external stimuli after muscle damage [14]. Moreover, quiescent fibroblasts exhibit high metabolic activity [15] in

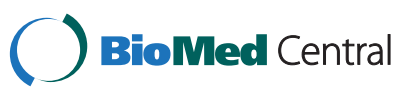


agreement with a quiescent state that is far from 'quiet'. Interestingly, a growing pool of data demonstrates that cell fate determination is reliant on post-transcriptional gene regulation [16-20] and may provide mechanisms to maintain quiescent satellite cells in a ready state.

One such RNA post-transcriptional mechanism, microRNA-mediated gene silencing, regulates skeletal muscle specification and myogenic differentiation [21-23]. MicroRNAs (miRNA) are a class of small non-coding RNAs that bind to target mRNA in a sequence specific manner to mediate gene silencing [24-27] and can target and silence protein expression from tens to hundreds of mRNAs [26,27]. Furthermore, miRNAs modulate stem cell fate decisions [28-31] and may have similar functions in satellite cells. Recent studies identify miR-489 and miR-206 expression in quiescent satellite cells [32,33], however, it is likely that many uncharacterized miRNAs play roles in the transition of a quiescent satellite cell to transit-amplifying myoblast.

To understand the mechanisms involved in satellite cell activation, we previously screened a number of candidate genes for changes in expression from freshly isolated satellite cells and from satellite cells isolated at either $12 \mathrm{~h}$ post-muscle injury or $48 \mathrm{~h}$ post-muscle injury to represent quiescent, activated, and proliferating satellite cells, respectively. Although unbiased gene expression screens have been performed on satellite cells, these studies have either compared freshly isolated satellite cells to satellite cells expanded in culture [14,34] or to satellite cells in diseased skeletal muscle [14]. Neither of these studies directly compared satellite cells prior to and following induced muscle injury in vivo and thus, the reported gene expression changes specific to cell culture or specific to diseased muscle may not reliably identify gene expression changes associated with satellite cell activation in vivo. Here, we report global gene expression profiles and candidate miRNAs associated with quiescent and activated satellite cells as well as identify a novel function for miR-16, miR-106b, and miR-124 in satellite cell fate determination. From these analyses, we posit that satellite cell activation is primarily regulated by post-transcriptional gene regulation as opposed to transcriptional induction.

\section{Methods}

Mice

All animal procedures were performed according to protocol number 1012.01 approved by Institutional Animal Care and Use Committee at the University of Colorado at Boulder. Mice were housed in a pathogen-free environment at the University of Colorado at Boulder. All mice sacrificed were female and between 3 and 6 months of age. Wild type mice were C57Bl/6xDBA2 (B6D2F1/J, Jackson Labs) and syndecan $-4^{-/-}$mice carry homozygous deletion of syndecan-4 in the C57Bl/6 background [35].

\section{Fluorescence-activated cell sorting of satellite cells}

The tibialis anterior muscles of 3-month-old female B6D2F1/J or syndecan- $4^{-/-}$mice were injured by injection with $50 \mu \mathrm{L} 1.2 \% \mathrm{BaCl}_{2}$ in saline prior to harvest or harvested from uninjured hind limbs. The tibialis anterior muscles were dissected from the hind limb, minced, and digested in $400 \mathrm{U} / \mathrm{mL}$ collagenase in Ham's F-12C at $37^{\circ} \mathrm{C}$ for $1 \mathrm{~h}$, vortexing frequently. Collagenase was inactivated by the addition of horse serum and debris was removed by sequential straining through $70 \mu \mathrm{m}$ and $40 \mu \mathrm{m}$ cell strainers (BD Falcon). Cells were gently centrifuged and the cell pellets were incubated at $4^{\circ} \mathrm{C}$ with $1: 100$ rabbit antisyndecan-3 antibody in Ham's F-12C with $15 \%$ horse serum followed by an incubation on ice with Cy5 conjugated anti-rabbit-IgG (Molecular Probes). Satellite cells were sorted based on syndecan-3 immunoreactivity on a MoFlo Legacy cell sorter (Dako Cytomation) directly into RNA lysis buffer (PicoPure RNA Isolation kit, Arcturus).

\section{Myofiber explant culture and immunostaining}

All hind limb muscles were dissected, connective tissue removed, and individual muscle groups isolated followed by digestion in $400 \mathrm{U} / \mathrm{mL}$ collagenase in Ham's F-12C at $37^{\circ} \mathrm{C}$. Single myofibers were isolated and grown in Ham's F-12C supplemented with $15 \%$ horse serum and $0.5 \mathrm{nM}$ FGF-2 prior to fixation in 4\% PFA. Fibers were blocked in $10 \%$ normal goat serum in phosphate buffered saline followed by antibody staining. Primary antibodies were rabbit anti-cmet (Santa Cruz) at 1:100, mouse anti-MyoD (Novocastra) at 1:10, mouse anti-Pax7 at 1:5 (Developmental Studies Hybridoma Bank), and rabbit anti-MyoD C-20 at 1:500 (Santa Cruz Biotechnology). Secondary antibodies were Alexa-488 conjugated anti-mouse IgG, Alexa-594 conjugated anti-rabbit IgG, Alexa-555 conjugated antimouse IgG, and Alexa-647 conjugated anti-rabbit IgG (Molecular Probes). All images taken on a Nikon Eclipse E800 microscope with a Nikon 40x/0.75 differential interference contrast $M$ lens and analyzed with Slidebook (Intelligent Imaging Innovations, Inc.).

\section{Microarray hybridization}

RNA was isolated from satellite cells using the PicoPure RNA Isolation kit (Arcturus) followed by two rounds of linear T7-based amplification (RiboAmp HA kit: Arcturus). The RNA equivalent of 5,000 cells was hybridized to Affymetrix mouse 430v2 GeneGhips (MOE430v2) according to manufacturer's instructions. GeneChips were scanned at the University of Colorado at Boulder on an Affymetrix GeneChip Scanner 3000 and spot intensities were recovered in the GeneChip Operating System (Affymetrix).

\section{Microarray data processing and analysis}

All analysis was performed using Spotfire ${ }^{\mathrm{TM}}$ DecisionSite 2 for Microarray Analysis. The raw CEL data files were 
normalized using GC Robust Multi-array Analysis (GCRMA). The raw CEL data files, microarray metadata, and GCRMA normalized expression values were deposited in GEO datasets (GSE38870). One wild type freshly isolated satellite cell replicate consistently clustered with the wild type satellite cells $12 \mathrm{~h}$ post-injury replicates (via hierarchical, Self-Organizing Map (SOM), k-means) indicating myogenic commitment and was removed from our analysis. The hierarchical cluster and associated dendrogram were generated using the $\log _{2}$-value

\section{Table 1 Quantitive PCR primer sequences}

\begin{tabular}{|c|c|c|}
\hline Gene & Primer type & Sequence \\
\hline \multirow[t]{2}{*}{ GAPDH } & Forward & 5' - TGTGTCCGTCGTGGATCTGA - 3' \\
\hline & Reverse & 5' - CCTGCTTCACCACCTTCTTGA - 3' \\
\hline \multirow[t]{2}{*}{185} & Forward & $5^{\prime}$ - GCCGCTAGAGGTGAAATTCTTG - 3' \\
\hline & Reverse & 5' - CTTTCGCTCTGGTCCGTCTT - 3' \\
\hline \multirow[t]{2}{*}{ Celf4 } & Forward & 5' CCTGCTCATCTACCATCTGCC - 3' \\
\hline & Reverse & $5^{\prime}$ - GCTCACGAAGCCAAAGCATTT - 3' \\
\hline \multirow[t]{2}{*}{ Pabpn1 } & Forward & 5' - TITCCTTGCCCTGTTTCCCATGTC - 3' \\
\hline & Reverse & $5^{\prime}$ - AGTGACTGAAGGGAGCACCTCAAA - 3' \\
\hline \multirow[t]{2}{*}{ Ppargc1a } & Forward & 5' - TAGTTTGAGCCCTTGCTGGCTCTT - 3' \\
\hline & Reverse & $5^{\prime}$ - AGCTCAGTGAGGCTGATGTGTACT - 3' \\
\hline \multirow[t]{2}{*}{ Mbnl1 } & Forward & $5^{\prime}$ - AACTGGACAGAACCGGGAAGAACT - 3' \\
\hline & Reverse & $5^{\prime}$ - GCAAACTGCAACTTGTGACACGGA - 3' \\
\hline \multirow[t]{2}{*}{ Matr3 } & Forward & 5' - ATTGTGGATAGGGCCAGTCATGGT - 3' \\
\hline & Reverse & $5^{\prime}$ - TTGCATTTGAGACAAGTGGCCTGG - 3' \\
\hline \multirow[t]{2}{*}{ Sfrs3 } & Forward & $5^{\prime}$ - TGTGGCACTGTGGGTGGAATGATA - 3' \\
\hline & Reverse & $5^{\prime}$ - CTGAAAGGACACTGGCATCTGAGT - 3' \\
\hline \multirow[t]{2}{*}{ Zfp36 } & Forward & $5^{\prime}$ - TCTCTGCCATCTACGAGAGCC - 3' \\
\hline & Reverse & $5^{\prime}$ - CCAGTCAGGCGAGAGGTGA - 3' \\
\hline \multirow[t]{2}{*}{ Zfp36l1 } & Forward & 5' - GCTTTCGAGACCGCTCTTTCT - 3' \\
\hline & Reverse & $5^{\prime}$ - TTGTCCCCGTACTTACAGGCA - $3^{\prime}$ \\
\hline \multirow[t]{2}{*}{ Zfp36l2 } & Forward & $5^{\prime}$ - AGCGGCTCCCAGATCAACT - 3' \\
\hline & Reverse & $5^{\prime}$ - CGAAAGCGAAGGCGTTGTTA - 3' \\
\hline \multirow[t]{2}{*}{ Elavl1 } & Forward & $5^{\prime}$ - TGTGAGTCACCAGCTGCCAAGTAT - 3' \\
\hline & Reverse & $5^{\prime}$ - GAGGTGGTTCAAACCAACCAACCA - 3' \\
\hline \multirow[t]{2}{*}{ Cdk2 } & Forward & 5' - TCCTCTGAGAGCAGTGATGCA - 3' \\
\hline & Reverse & $5^{\prime}$ - TTCCCCCAATGACCTAACCAG - 3' \\
\hline \multirow[t]{2}{*}{ E2F3 } & Forward & 5' - GGTCCTGGATCTGAACAAGGC - 3' \\
\hline & Reverse & $5^{\prime}$ - CCTTCCAGCACGTTGGTGAT - 3' \\
\hline U6 & Reverse & 5' - AATTCGTGAAGCGTTCCATAT - 3' \\
\hline miR-16 & Reverse & $5^{\prime}$ - TAGCAGCACGTAAATATTGGCG - 3' \\
\hline miR-93 & Reverse & $5^{\prime}$ - CAAAGTGCTGTTCGTGCAGGTAG - 3' \\
\hline miR-106b & Reverse & $5^{\prime}$ - TAAAGTGCTGACAGTGCAGAT - 3' \\
\hline miR-107 & Reverse & $5^{\prime}$ - AGCAGCATTGTACAGGGCTATCA - 3' \\
\hline miR-124 & Reverse & $5^{\prime}$ - TAAGGCACGCGGTGAATGCC - 3' \\
\hline miR-200b & Reverse & $5^{\prime}$ - TAATACTGCCTGGTAATGATGA - 3' \\
\hline
\end{tabular}

Sequences for forward and reverse primers used to detect mRNAs or sequence of reverse primer used to detect miRNAs using the Ncode universal forward primer. for relative probe intensity using the Unweighted Pair Group Method with Arithmetic Mean (UPGMA) with Euclidean distance as the similarity measure. The significance between genotypes and time points was determined using the multifactor analysis of variance (ANOVA) with a false discovery rate (FDR) $\leq 0.05$ and Bonferroni adjustment. Fold change was calculated as $2^{\text {abs(difference) }}$, where difference is the $\log _{2}$ difference between samples compared. Venn diagrams were generated in Spotfire ${ }^{\mathrm{TM}}$ using the list comparison function.

\section{Gene ontology and biological pathway analysis}

Unique gene identifiers (gene symbol, entrez gene ID, or Affymetrix probeset ID) were uploaded to the Database for Annotation, Visualization and Integrated Discovery (DAVID http://david.abcc.ncifcrf.gov/), FunNet (http:// www.funnet.info/), and ProfCom (http://webclu.bio.wzw. tum.de/profcom/). The mouse genome reference dataset for each algorithm was used as background. No further settings were required for DAVID. Analysis setting for FunNet were conventional functional analysis with the specificity enrichment computation for $\mathrm{GO}$ and false discovery rate $\leq 5 \%$. Analysis settings for ProfCom were up degree 1 and exclude. The default settings for each algorithm were used to identify enriched GO terms. Affymetrix probeset IDs and the $\log _{2}$ difference between wild type freshly isolated satellite cells and satellite cells isolated $12 \mathrm{~h}$ post-injury were uploaded and analyzed using IPA v9.0 (Ingenuity ${ }^{\circledR}$ Systems www.ingenuity. com). Analysis settings were to consider both all direct and indirect molecules and/or relationships using the Mouse Genome 4302.0 Array as a reference dataset.

\section{Computational prediction of miRNAs}

The Srivastava lab algorithm assessed mRNA sequences in human, mouse, and rat for miRNA seed matches and required base-paring of miRNA nucleotides 2 to 7 with binding energy $\leq-14 \mathrm{kcal} / \mathrm{mol}$ and flanking energy $\geq-7$ $\mathrm{kcal} / \mathrm{mol}$. Secondary structure was used to eliminate false-positives by removing those seed matches with secondary elements that stabilize mRNA. Priority 1 calls had a destabilizing mRNA element while Priority 2 calls did not contain a destabilizing element in at least one species. GeneAct used the miRanda algorithm to identify miRNA target sites across three mammalian species. False-positives were eliminated with the differential binding site search against genes that were constitutively expressed in satellite cells.

\section{RNA isolation}

mRNA was extracted from satellite cells using the RNeasy Kit according to the manufacturer's protocol (Qiagen). miRNA was extracted using both the RNAqueous-micro kit the mirVana miRNA isolation kit according to the 


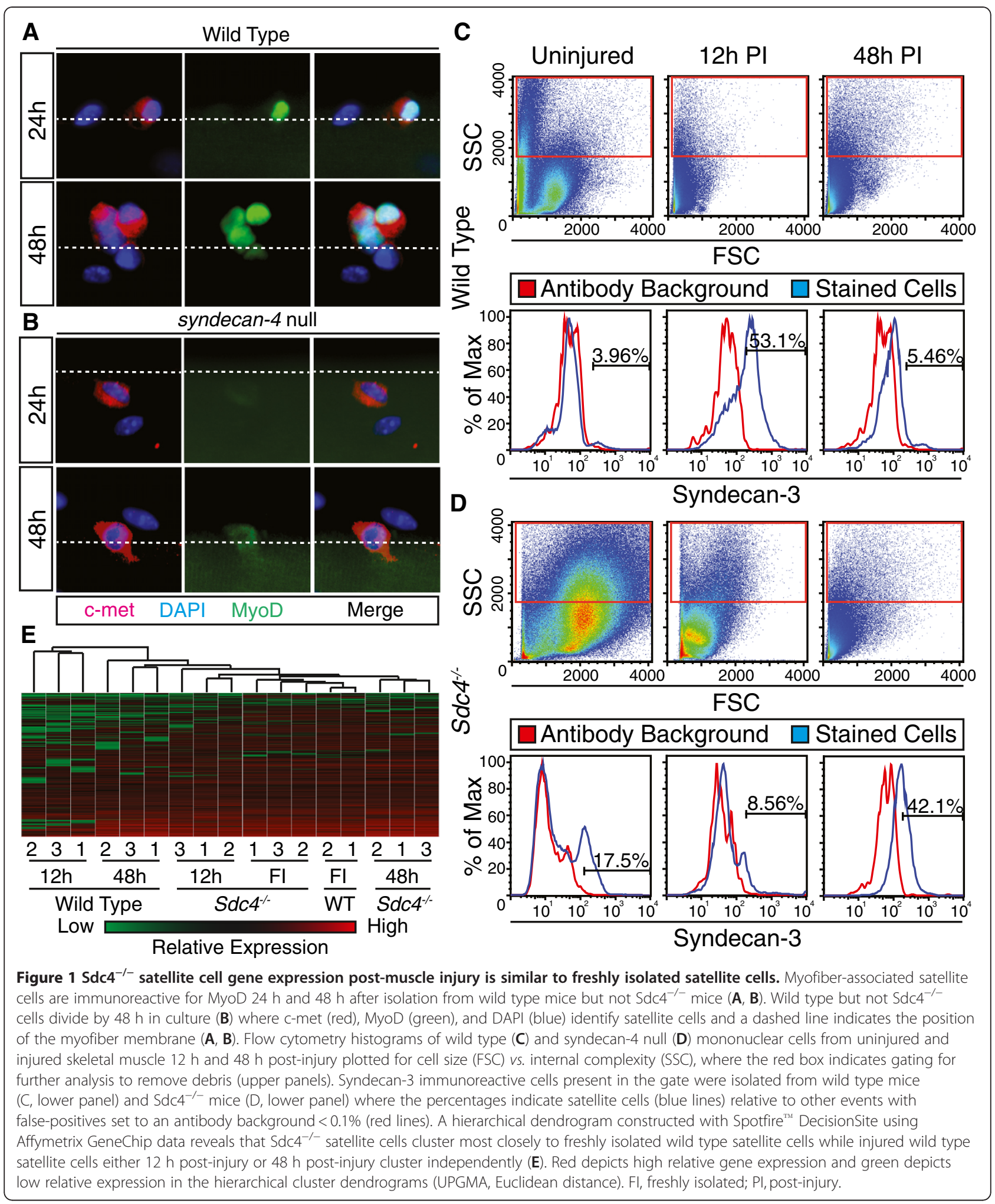


manufacturer's protocols (Ambion) with the following modifications. For satellite cells, the mirVana manufacturer's protocol was followed using volumes and columns for the RNAqueous-micro kit. For MM14 cells, the mirVana manufacturer's protocol was followed. RNA concentration was determined using a NanoDrop 2000 spectrophotometer (Thermo Scientific).

\section{Quantitative RT-PCR}

The Superscript III First Strand cDNA Synthesis kit was used to generate cDNA from mRNA according to manufacturer's instructions (Invitrogen). The Ncode miRNA qRT-PCR system (Invitrogen) was used to generate cDNA from miRNA according to manufacturer's instructions. Briefly, RNA was poly-adenylated with Poly-A polymerase followed by cDNA transcription with Superscript III reverse transcriptase using a primer similar to Oligo-dT with a unique 5' end. Quantitative RT-PCR was performed using SYBR-Green (Applied Biosystems) or SYBR-GreenER (Invitrogen) on either an ABI 7500 Fast or ABI 7900 Real-Time PCR machine (Applied Biosystems). Primer sequences are listed in Table 1.

\section{RNase protection assay}

Candidate miRNAs were screened using the mirVana miRNA detection kit according to the manufacturer's protocol (Ambion). All probes were radio-labeled with ${ }^{32} \mathrm{P}-\mathrm{UTP}$ using the mirVana miRNA probe construction kit (Ambion) according to manufacturer's protocol.

\section{Isolation of quiescent satellite cells}

Quiescent satellite cells were isolated following IP injection with $75 \mathrm{mg} / \mathrm{kg}$ of SB203580 (Alexis Corporation) and kept in $25 \mu \mathrm{M}$ SB203580 through the isolation as described (Hausburg et al., Submitted). All satellite cells were isolated as follows. Hind limb muscles of 3- to

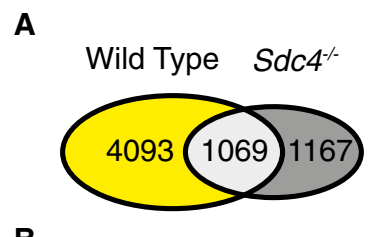

B

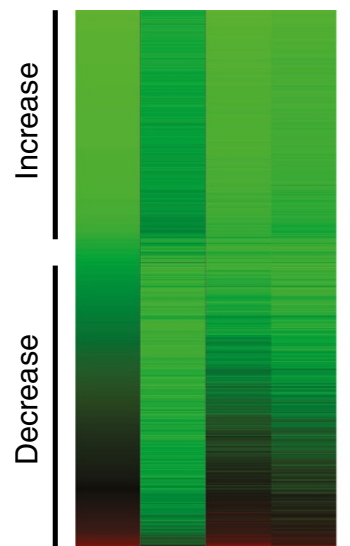

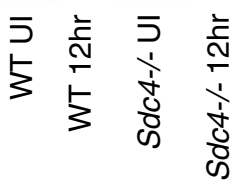

Low $\square$ High

Relative Expression
C

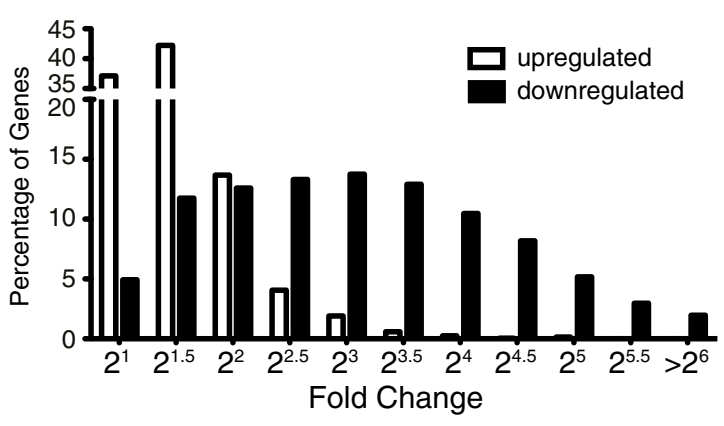

D
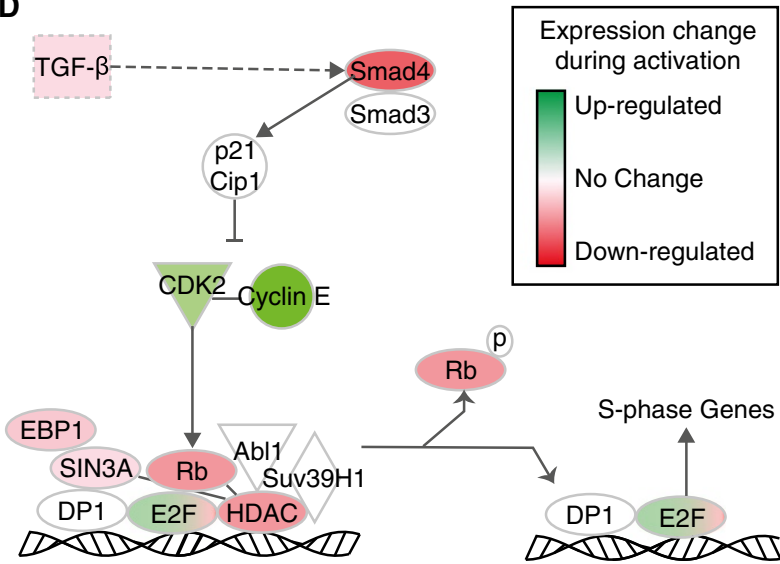

Rb-dependent repression of E2F-mediated transcription

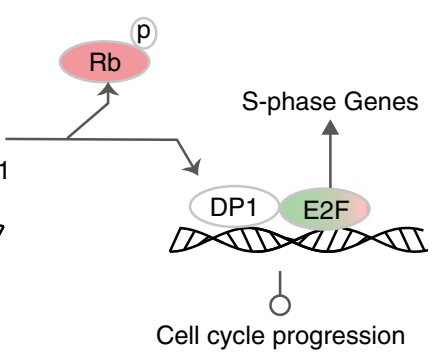

Figure 2 Gene expression changes occurring during satellite cell activation. The genes significantly regulated between freshly isolated satellite cells and satellite cells isolated $12 \mathrm{~h}$ post-injury from wild type and $\mathrm{Sdc} 4^{-/-}$mice were plotted as a Venn diagram to identify genes unique to wild type satellite cells ( $\mathbf{A}$, yellow, ANOVA $P \leq 0.01, \geq$ two-fold change). A heat map depicting changes in relative expression of genes unique to wild type satellite cells with more than half (56\%) of the transcripts decreasing during the first $12 \mathrm{~h}$ following satellite cell activation (B, red is high relative expression and green low relative expression). The frequency of genes that decrease ( $\mathbf{m})$ more than four-fold $\left(2^{2}\right)$ is significantly higher than the frequency of genes that increase ( $($ ) $)$ more than four-fold $\left(2^{2}\right)$ during the first $12 \mathrm{~h}$ post-muscle injury (C). Further analysis of gene expression data using IPA 9.0 (Ingenuity ${ }^{\circledR}$ Systems, www.ingenuity.com) demonstrate that genes promoting cell cycle progression increase (green) while genes that inhibit the G1/S phase transition decrease (red) in wild type satellite cells $12 \mathrm{~h}$ post-muscle injury (D, relative intensity depicts the fold change with higher color intensity denoting a greater fold change). 
A

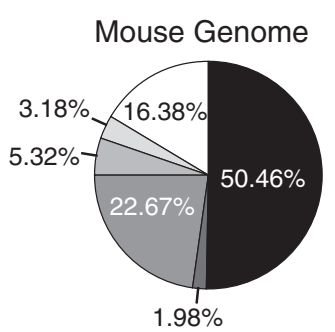

Satellite Cell Activation

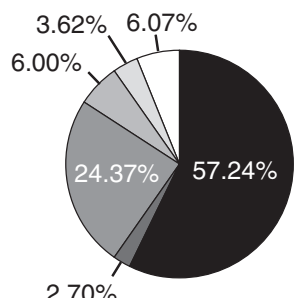

$2.70 \%$

Binding

Structural molecule activity

$\square$ Catalytic activity

$\square$ Transcription regulator activity

$\square$ Enzyme regulator activity

Other
B

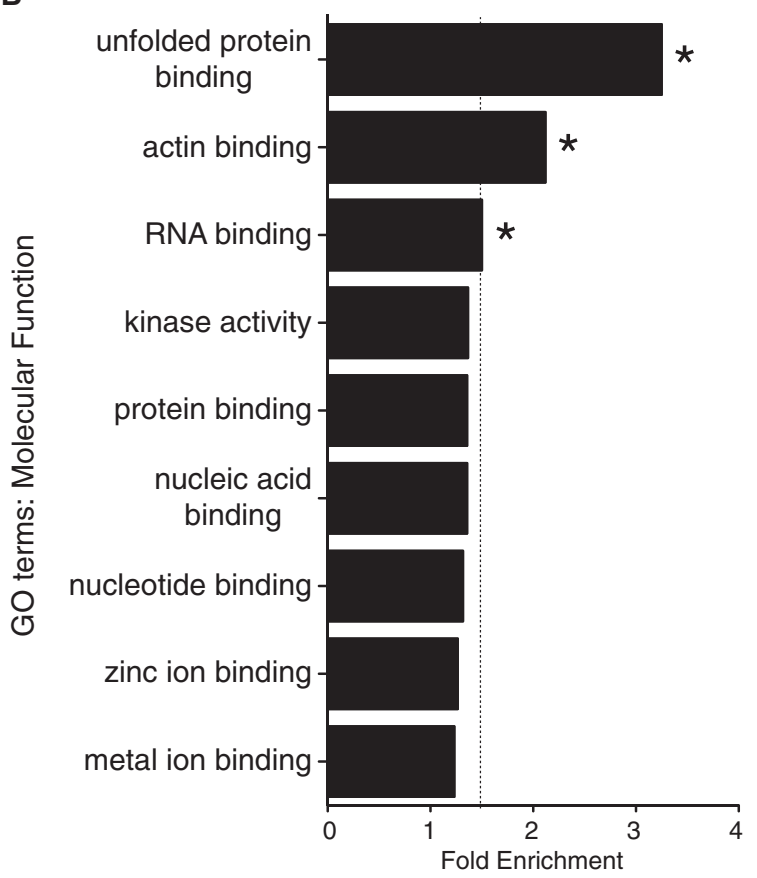

Figure 3 Binding genes are enriched during satellite cell activation. Gene expression changes unique to wild type satellite cells occurring within $12 \mathrm{~h}$ post-muscle injury were further analyzed by gene ontology. The general Molecular Function GO categories of Binding $\left(P=7.03 \times 10^{-43}\right)$, Structural molecule activity $\left(P=4.97 \times 10^{-4}\right)$, Catalytic activity $\left(P=1.46 \times 10^{-3}\right)$, Transcription regulator activity $(P=0.0229)$, and Enzyme regulator activity $(P=0.0521)$ were identified by DAVID as enriched when comparing satellite cells isolated $12 \mathrm{~h}$ post-muscle injury to freshly isolated satellite cells (A). Specific Molecular Function GO terms including RNA binding, unfolded protein binding, and actin binding were enriched an average of 1.5-fold when comparing satellite cells from injured and uninjured muscle as identified by three independent algorithms including ProfCom, FunNet, and DAVID (B). The dotted line marks a 1.5-fold enrichment threshold. Asterisks mark GO terms with an average enrichment $\geq 1.5$-fold.

6-month-old female B6D2F1/J mice were dissected and digested in $400 \mathrm{U} / \mathrm{mL}$ collagenase in Ham's F- $12 \mathrm{C}$ at $37^{\circ} \mathrm{C}$ for $1 \mathrm{~h}$ with periodic vortexing. The collagenase was inactivated with horse serum and debris was removed with sequential straining through $70 \mu \mathrm{m}$ and $40 \mu \mathrm{m}$ cell strainers (BD Falcon). Satellite cells were either isolated at the interface of a $40 \% / 70 \%$ percoll gradient (GE Healthcare) or plated in Ham's F-12C supplemented with
$15 \%$ horse serum and $0.5 \mathrm{nM}$ FGF-2 for various times before RNA isolation.

\section{miRNA inhibition}

Myofiber explant cultures were transfected using Lipofectamine 2000 (Invitrogen) according to manufacturer's protocol with a 2.5:1 ratio of lipofectamine: nucleic acid. 200nM miRIDIAN hairpin inhibitors

Table 2 Identified Molecular Function GO terms

\begin{tabular}{|c|c|c|c|c|c|c|}
\hline GO Term & DAVID & $P$ value & ProfCom & $P$ value & FunNet & $P$ value \\
\hline Unfolded protein binding & 2.27 & $2.74 \mathrm{E}-05$ & 4.65 & 2.90E-08 & 2.83 & 2.64E-08 \\
\hline Actin binding & 1.83 & $2.00 \mathrm{E}-09$ & 2.60 & $2.10 \mathrm{E}-12$ & 1.92 & $5.03 \mathrm{E}-10$ \\
\hline RNA binding & 1.30 & $3.25 \mathrm{E}-04$ & 1.82 & 9.80E-10 & 1.39 & $6.98 \mathrm{E}-05$ \\
\hline Kinase activity & 1.25 & 7.15E-04 & 1.54 & 4.30E-08 & 1.31 & $1.48 \mathrm{E}-04$ \\
\hline Protein binding & 1.25 & $8.42 \mathrm{E}-29$ & 1.52 & $5.90 \mathrm{E}-70$ & 1.30 & $1.86 \mathrm{E}-21$ \\
\hline Nucleic acid binding & 1.13 & $2.38 \mathrm{E}-04$ & 1.63 & $7.50 \mathrm{E}-10$ & 1.31 & $7.34 \mathrm{E}-05$ \\
\hline Nucleotide binding & 1.21 & $6.45 \mathrm{E}-07$ & 1.50 & $6.10 \mathrm{E}-18$ & 1.23 & $2.76 \mathrm{E}-06$ \\
\hline Zinc ion binding & 1.19 & $1.83 \mathrm{E}-05$ & 1.38 & $1.80 \mathrm{E}-15$ & 1.23 & $5.01 \mathrm{E}-05$ \\
\hline Metal ion binding & 1.17 & 7.66E-09 & 1.37 & $5.20 \mathrm{E}-23$ & 1.16 & 4.83E-05 \\
\hline
\end{tabular}

Fold enrichment and associated p-values for the Molecular Function GO terms shared between three independent gene ontological analyses using DAVID (http:// david.abcc.ncifcrf.gov), profcom (http://webclu.bio.wzw.tum.de/profcom/), and FunNet (http://www.funnet.info). 
(Dharmacon) against miR-16, miR-93, miR-106b, and miR-124 were co-transfected with pEGFP-C1-H2B. Scrambled control was the miRIDIAN hairpin inhibitor negative control 1 (Dharmacon).

\section{Results}

Identification of gene expression changes associated with satellite cell activation in vivo

An unbiased global gene expression analysis using Affymetrix GeneChips was performed to identify changes occurring during the transition of satellite cells from quiescence to a population of proliferating myoblasts in vivo. To accomplish this, we identified changes in gene expression profiles between freshly isolated satellite cells and satellite cells isolated $12 \mathrm{~h}$ or $48 \mathrm{~h}$ following $\mathrm{BaCl}_{2}$ induced muscle injury. The time points chosen correspond to activated satellite cells which do not express MyoD protein (freshly isolated), committed myoblasts marked by MyoD expression (12 h post-muscle injury), and proliferating myoblasts (48 $\mathrm{h}$ post-muscle injury; Figure 1A) [36,37]. Syndecan-4 null satellite cells fail to activate, express MyoD, or enter the cell cycle appropriately within $48 \mathrm{~h}$ post-injury, and are incapable of skeletal muscle repair (Figure 1B) [36,37]. Therefore, we eliminated the genes whose expression changes following a muscle injury in Sdc4 ${ }^{-1-}$ satellite cells from our analyses as these genes were unlikely to be involved in satellite cell activation. Wild type and Sdc4 ${ }^{-1-}$ satellite cells were isolated by fluorescence activated cell sorting (FACS) using anti-syndecan-3 antibodies as a marker for quiescent and proliferating satellite cells [38] from uninjured tibialis anterior (TA) muscle (Figure $1 \mathrm{C}$ ) and TA muscles $12 \mathrm{~h}$ post-injury (Figure 1D).

RNA was extracted from the isolated cells and processed for hybridization to Affymetrix v2.0 mouse GeneChips. The GeneChip data (Additional file 1, Additional file 2, Additional file 3, Additional file 4, Additional file 5, Additional file 6) were analyzed with Spotfire ${ }^{\mathrm{TM}}$ DecisionSite for Microarry Analysis software and an initial hierarchical cluster dendrogram generated. Visualization of the relationships between gene expression profiles show $\mathrm{Sdc} 4^{-/-}$samples, regardless of time post-injury, cluster

Table 3 Top 25 ranking biological interaction networks enriched during satellite cell activation

\begin{tabular}{|c|c|c|}
\hline Rank & Associated network function & Score \\
\hline 1 & RNA post-transcriptional modification, developmental disorder, genetic disorder & 34 \\
\hline 2 & Genetic disorder, neurological disease, psychological disorders & 34 \\
\hline 3 & Genetic disorder, cellular assembly and organization, skeletal and muscular disorders & 34 \\
\hline 4 & Lipid metabolism, small molecule biochemistry, vitamin and mineral metabolism & 32 \\
\hline 5 & Nervous system development and function, tissue morphology, cellular development & 32 \\
\hline 6 & Genetic disorder, metabolic disease, molecular transport & 32 \\
\hline 7 & Cell morphology, cell-to-cell signaling and interaction, cellular assembly and organization & 32 \\
\hline 8 & Genetic disorder, ophthalmic disease, cardiovascular disease & 32 \\
\hline 9 & Post-translational modification, cardiovascular disease, cardiovascular system development and function & 32 \\
\hline 10 & Amino acid metabolism, genetic disorder, metabolic disease & 32 \\
\hline 11 & Cardiovascular system development and function, cell morphology, cell-to-cell signaling and interaction & 32 \\
\hline 12 & Dermatological diseases and conditions, genetic disorder, amino acid metabolism & 32 \\
\hline 13 & Organismal functions, cardiac stenosis, cardiovascular disease & 32 \\
\hline 14 & Cellular assembly and organization, RNA post-transcriptional modification, cancer & 32 \\
\hline 15 & Carbohydrate metabolism, drug metabolism, nucleic acid metabolism & 32 \\
\hline 16 & Gene expression, amino ccid metabolism, small molecule biochemistry & 32 \\
\hline 17 & Cell cycle, reproductive system development and function, cell morphology & 32 \\
\hline 18 & Genetic disorder, neurological disease, psychological disorders & 32 \\
\hline 19 & Cancer, cellular assembly and organization, cellular compromise & 32 \\
\hline 20 & Cell cycle, cell death, cell morphology & 30 \\
\hline 21 & Genetic disorder, metabolic disease, neurological disease & 30 \\
\hline 22 & Post-translational modification, protein degradation, protein synthesis & 29 \\
\hline 23 & Cell signaling, cardiovascular disease, skeletal and muscular system development and function & 29 \\
\hline 24 & Lipid metabolism, small molecule biochemistry, dermatological diseases and conditions & 29 \\
\hline 25 & Cellular development, genetic disorder, hematological system development and function & 29 \\
\hline
\end{tabular}

The most significantly enriched biological networks during satellite cell activation were generated through the use of IPA 9.0 (Ingenuity Systems, www.ingenuity. com). The score is the negative base- 10 logarithm of the $P$ value (that is, a score of 34 is $P \leq 10^{-34}$ ). 
Table 4 Genes in the top ranked network associate with muscle function, muscle disease, or fate determination

\begin{tabular}{lll}
\hline Genes & Relevant role/Disease/Expression & Reference \\
\hline Luc7l & Regulation of muscle differentiation & {$[45]$} \\
\hline Snrpn & Prader-Willi syndrome & {$[46]$} \\
\hline Polr2a & Positive regulation of embryonic stem cells & {$[47]$} \\
\hline Htatsf1 & Expression in developing limb bud & {$[48]$} \\
\hline Zbtb3 & Expression in developing limb bud & {$[48]$} \\
\hline Supt5h & Expression in developing limb bud & {$[48]$} \\
\hline Tcerg1 & Expression in developing limb bud & {$[48]$} \\
\hline Pabp1 & Facilitates neuronal proliferation and maturation; & {$[48,49]$} \\
& Expression in developing limb bud & \\
\hline Snrpb & Spinal muscular atrophy; Expression in & {$[7,48]$} \\
& developing limb bud and somite & {$[50]$} \\
\hline Snrpa1 & Spinal muscular atrophy & {$[50]$} \\
\hline Syncrip & Spinal muscular atrophy & {$[48]$} \\
\hline Sf1 & Expression in developing limb bud & {$[51]$} \\
\hline AP3D1 & Regulation of progenitor cell competence & {$[48]$} \\
\hline Hnrnpr & Expression in developing limb bud &
\end{tabular}

Fourteen of the thirty-five genes in the top ranked biological network as identified by IPA v9.0 (Ingenuity ${ }^{\circledR}$ Systems, www.ingenuity.com) have defined functions in muscle or cell fate determination as determined with the associated references.

with freshly isolated wild type satellite cells (Figure 1E) supporting our observations that $\mathrm{Sdc}^{-/-}$satellite cells do not activate appropriately within $48 \mathrm{~h}$ following an induced muscle injury (Figure 1A, B). Within the wild type dataset, we observed that committed myoblasts isolated $12 \mathrm{~h}$ post-injury exhibited the most divergent gene expression profiles, suggesting that these committed satellite cells differ substantially from either quiescent satellite cells or proliferating myoblasts (Figure 1E). To focus on genes that may be involved in satellite cell activation, we chose to further compare gene expression changes occurring within the first $12 \mathrm{~h}$ post-muscle injury.

\section{Over 4,000 genes are specifically regulated during satellite cell activation}

A comparative analysis of gene expression profiles from wild type and Sdc4 ${ }^{-/-}$satellite cells within the first $12 \mathrm{~h}$ following satellite cell activation identified a cohort of genes unique to satellite cell activation. In wild type satellite cells, 5,162 genes change significantly between satellite cells isolated from uninjured muscle and those isolated $12 \mathrm{~h}$ post-injury as defined by $\mathrm{a} \geq 2$-fold change with an ANOVA $P \leq 0.01$ (Figure 2A). In contrast, 2,236 genes similarly changed expression in $\mathrm{Sdc}^{-/-}$ satellite cells isolated from uninjured TA muscle and TA muscles $12 \mathrm{~h}$ post-injury (Figure 2A). Eighty percent $(4,093)$ of the genes differentially expressed in WT satellite cells do not significantly change in Sdc4 $4^{-/-}$ satellite cells as identified by Venn analysis (Figure 2A, $\mathrm{B}$; Additional file 7). We reasoned that the metabolic changes occurring during satellite cell activation as well as the induction of the transcription factor MyoD and cell cycle entry would result in a large cohort of induced genes. Surprisingly, more than half $(56 \%)$ of the genes differentially expressed in satellite cells by $12 \mathrm{~h}$ postinjury decrease in relative expression (Figure 2B). Moreover, the magnitude of change for genes that decrease is on average three-fold greater than the magnitude of change for genes that increase following muscle injury. Less than $10 \%$ of genes whose expression is increased change more than four-fold $\left(2^{2}\right)$, while $70 \%$ of downregulated genes change more than four-fold $\left(2^{2}\right)$ and 3\% decrease more than 64-fold $\left(2^{6}\right)$ (Figure 2C). These observations suggest that quiescent satellite cells express a cohort of genes that maintains and regulates the quiescent state, are likely critical for interaction with the satellite cell niche, and are necessary for interpreting signals for exit from quiescence. Furthermore, our results support the idea that satellite cell quiescence is actively maintained, consistent with a prior report examining freshly isolated satellite cells and satellite cells isolated from dystrophic muscle [14].

To further test the idea that satellite cell quiescence is actively maintained, we analyzed genes in the cohort that significantly change $12 \mathrm{~h}$ post-injury involved in cell cycle progression. We would expect cell cycle progression genes to be induced during activation and found that genes modulating the G1/S phase transition are among those that increase in relative expression (Figure 2D, green). In contrast, cell cycle inhibitors decrease in relative expression (Figure 2D, red) as expected for the transition of satellite cells from mitotic quiescence to an activated state in preparation for cell cycle entry. Moreover, these genes do not change expression significantly in $\mathrm{Sdc}_{4}{ }^{-/}$ satellite cells $12 \mathrm{~h}$ post-injury (Figure 2A, B; Additional file 7) consistent with their impaired cell cycle activation and MyoD induction.

Genes involved in RNA post-transcriptional regulation are significantly enriched during satellite cell activation

Gene ontology (GO) classifications were used to aid in identifying potential mechanisms regulating satellite cell activation. The Database for Annotation, Visualization and Integrated Discovery (DAVID) was used to identify enrichment of general molecular function categories $[39,40]$ during activation of satellite cells. The GO category of Molecular Function: Binding is the most significantly over-represented GO category during satellite cell activation $\left(P\right.$ value $=7.03 \times 10^{-43}$ compared to the mouse genome), where a $7 \%$ increase in the total percentage of genes classified as binding occurs in satellite cells within the first $12 \mathrm{~h}$ post-muscle injury (Figure 3A). Further refinement of ontological categories reveals that $\mathrm{GO}$ terms unfolded protein binding, actin binding, and 
RNA binding were enriched an average of 1.5 -fold over three independent gene annotation algorithms: FunNet [41,42], ProfCom [43], and DAVID [39,40] (Figure 3B, Table 2). Thus, in the first $12 \mathrm{~h}$ post-muscle injury, major changes occur in genes involved in RNA binding, the unfolded protein response, and in actin binding. The changes in RNA binding proteins and unfolded protein response may be involved in the downregulation of genes necessary to maintain a quiescent satellite cell, while changes in actin binding are likely to reflect changes in satellite cell motility [44] that accompany repair of skeletal muscle tissue.

A fourth independent analysis focused on biological networks (IPA-Ingenuity Pathway Analysis www.ingenuity. com) ranked RNA Post-Transcriptional Modification in the top biological network (Table 3; Table 4). Thus, from four independent methods of gene expression analysis, a much higher proportion of genes involved in posttranscriptional RNA regulation change expression in the transition from a quiescent satellite cell to a committed myoblast, suggesting a role for post-transcriptional regulation of RNA in this transition. Therefore, we further analyzed genes involved in RNA post-transcriptional modification to further characterize individual genes and to develop hypotheses regarding the function of these genes in the transition of satellite cells from mitotic quiescence to cell cycle entry.

\section{Splicing factors are preferentially downregulated during satellite cell activation}

The top ranking biological network identified by IPA has associated biological functions of RNA Post-Transcriptional Modification, Developmental Disorder, and Genetic Disorder (Table 3), where RNA Post-Transcriptional Modification includes mRNA decay and stabilization, mRNA splicing, and miRNA-mediated gene silencing. When we examined genes within this network, nearly half of the genes whose expression changes during satellite

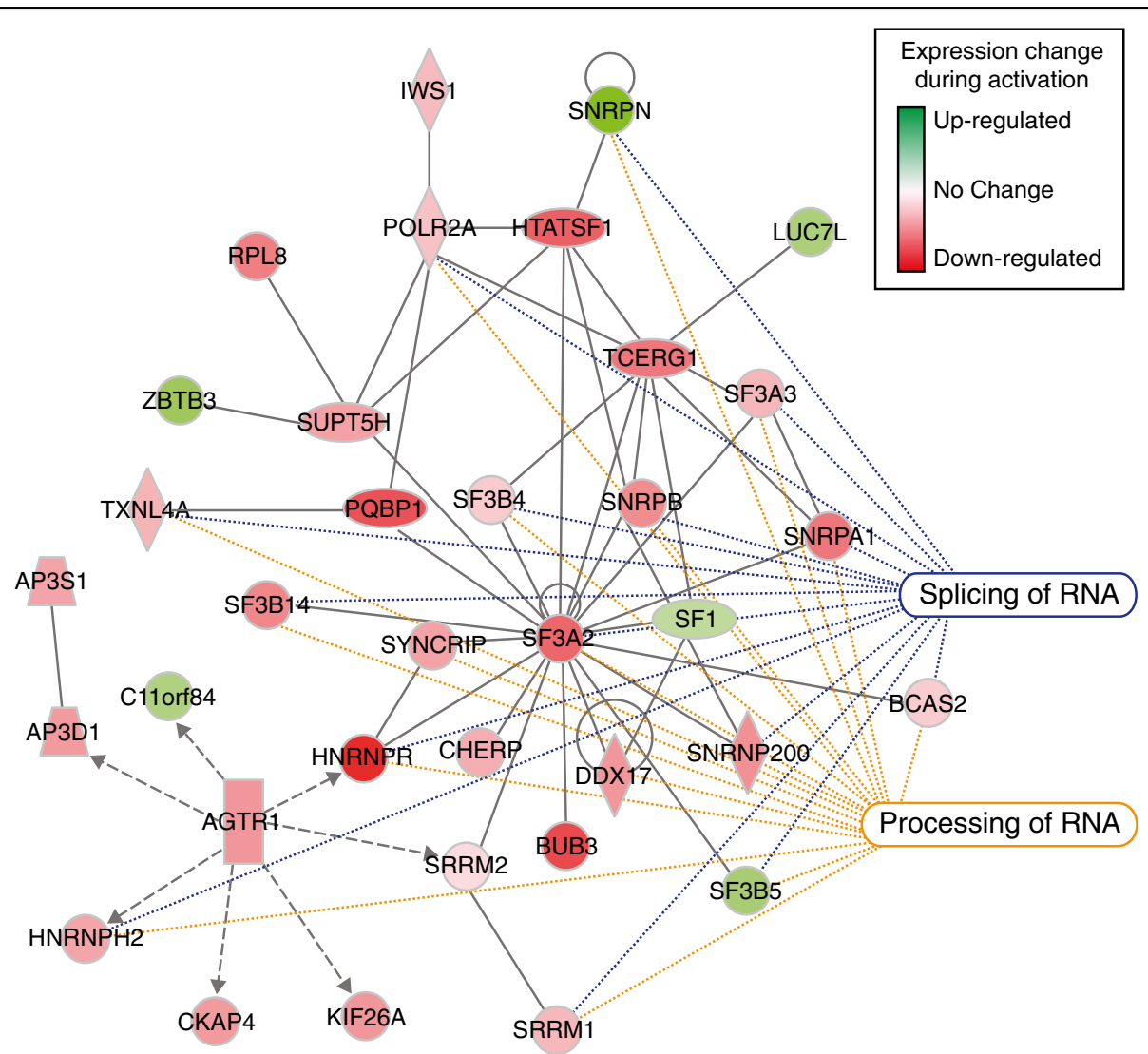

Figure 4 RNA post-transcriptional modification is the most enriched biological network. Gene expression changes unique to wild type satellite cell activation were subjected to IPA 9.0 (Ingenuity ${ }^{\circledR}$ Systems, www.ingenuity.com) network analysis and RNA Post-Transcriptional Modification, Developmental Disorder, Genetic Disorder $\left(P \leq 10^{-34}\right)$ emerged as the associated biological functions in the top ranked interaction network with the canonical pathways Processing of RNA (17 blue dotted lines, $P \leq 4.44 \mathrm{e}-22$ ) and Splicing of RNA (15 orange dotted lines, $P \leq 7.64 \mathrm{e}-20$ ) comprising $50 \%$ of this network. The functions of these genes in muscle disease and cell fate decisions are listed in Table 4. Red indicates genes down-regulated and green indicates genes upregulated with the intensity denoting the increase or decrease in fold change. The data compares genes unique to wild type satellite cells isolated $12 \mathrm{~h}$ post-injury to satellite cells isolated from uninjured skeletal muscle. 


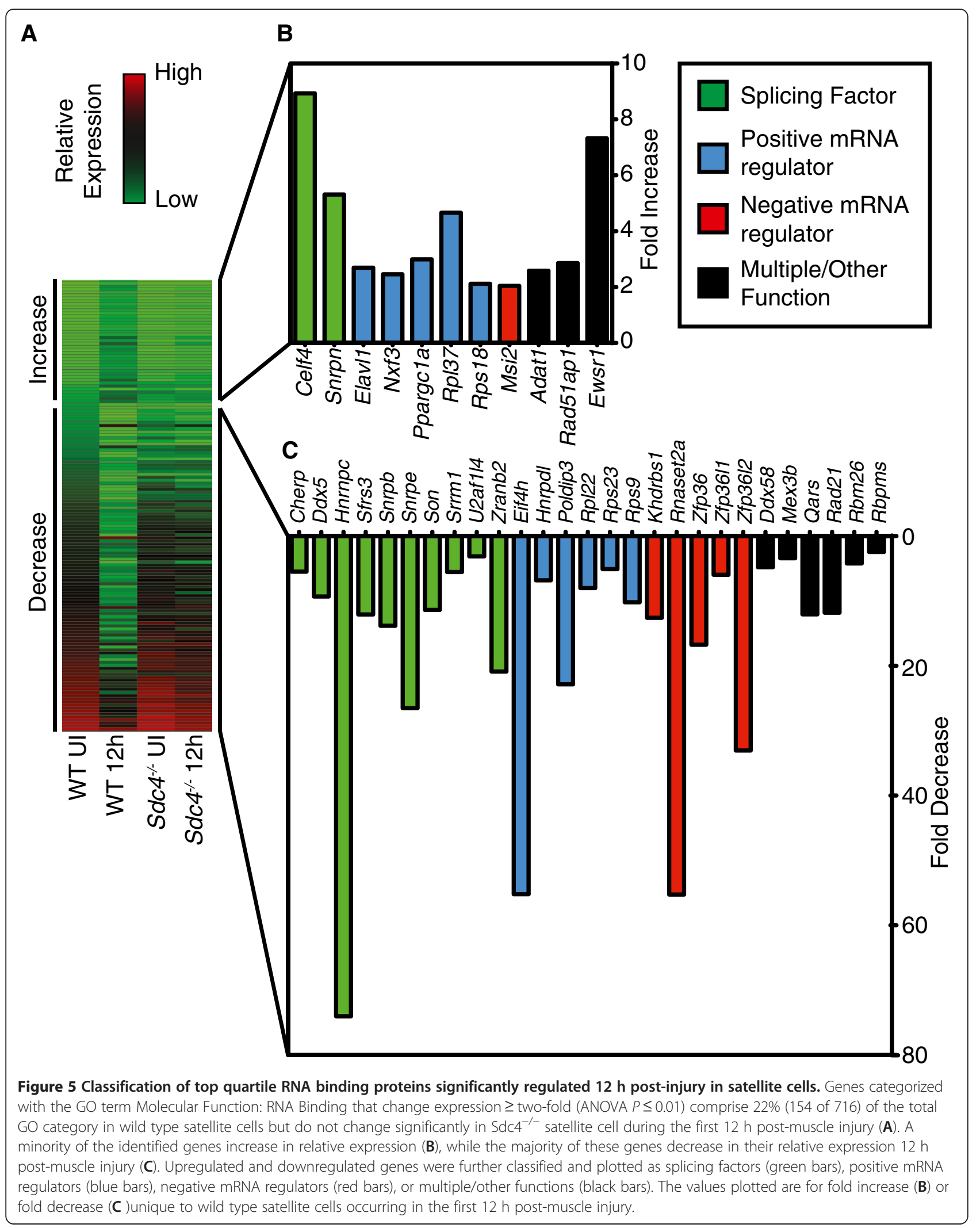


Table 5 Microarray and qPCR expression trends correlate for RNA binding proteins

\begin{tabular}{llllll}
\hline Gene & Microarray & qPCR & Fold change & Correlation & Biological function \\
\hline Celf4 & $\uparrow$ & $\uparrow$ & 2.51 & Yes & Splicing factor \\
\hline Pabpn1 & $\downarrow$ & $\downarrow$ & -1.80 & Yes & Positive mRNA regulator \\
\hline Ppargc1a & $\uparrow$ & $\uparrow$ & 1.34 & Yes & Positive mRNA regulator \\
\hline Mbnl1 & $\downarrow$ & $\downarrow$ & -1.14 & Yes & Splicing factor \\
\hline Matr3 & $\downarrow$ & $\uparrow$ & 11.79 & No & Splicing factor \\
\hline Sfrs3 & $\downarrow$ & $\uparrow$ & 19.11 & No & Negative mRNA regulator \\
\hline Zfp36 & $\downarrow$ & $\downarrow$ & -2.87 & Yes & Negative mRNA regulator \\
\hline Zfp3611 & $\downarrow$ & $\downarrow$ & -4.48 & Yes & Negative mRNA regulator \\
\hline Zfp3612 & $\downarrow$ & $\downarrow$ & -1.63 & Yes & Positive mRNA regulator \\
\hline Elav11 & $\uparrow$ & $\uparrow$ & 3.01 & Yes & Promotes cell cycle entry \\
\hline Cdk2 & $\uparrow$ & $\uparrow$ & 10.28 & Yes & Promotes cell cycle entry \\
\hline E2F3 & $\uparrow$ & $\uparrow$ & 12.90 & &
\end{tabular}

Eight of ten RNA binding proteins and two cell cycle genes validate expression changes between wild type satellite cells isolated from uninjured TA muscle and from the TA $12 \mathrm{~h}$ post-muscle injury. Arrows show increase $(\uparrow)$ and decrease $(\downarrow)$ for both microarray and qPCR during satellite cell activation. Fold change is from qPCR data where positive values indicate increased expression and negative valued indicate decreased expression between satellite cells isolated from uninjured TA muscle and from the TA $12 \mathrm{~h}$ post-muscle injury. Quantitative PCR data is normalized to GAPDH or $18 \mathrm{~S}$.

cell activation are involved in RNA processing and splicing (Figure 4). Moreover, many genes in this interaction network are implicated in either muscle function, muscle disease, or cell fate decisions (Table 4). Consistent with our prior observations that downregulated genes exhibit greater fold change in relative expression occurring during the first $12 \mathrm{~h}$ post-muscle injury, the majority of RNA processing and splicing genes identified in the interaction network ( $87 \%$ and $88 \%$, respectively) decrease postmuscle injury (Figure 4). Furthermore, of the 154 RNA binding proteins identified by GO analysis (Figure 3B, Additional file 8), 69\% decrease in relative expression (Figure 5A; Additional file 8). These data show that RNA binding proteins are highly overrepresented in quiescent satellite cells and suggest that regulation of RNA plays an important role in maintaining the quiescent state and in the transition to a cycling myoblast.

An examination of the top quartile of RNA binding proteins with the most significant changes in expression reveal that the majority (45\%) of upregulated genes are positive mRNA regulators (Figure $5 \mathrm{~B}$ ), while downregulated genes include a similar distribution of all RNA protein functions with splicing factors exhibiting a slight majority (37\%: Figure 5C). Furthermore, 24\% of the previously identified RNA processing of splicing factors (Figure 4) are present in this top quartile. To confirm the microarray expression data, we performed qPCR validation finding that approximately $80 \%$ of the tested RNA binding proteins and both tested cell cycle regulators have consistent gene expression profiles (Table 5). Thus, genes involved in mRNA regulation may play diverse roles in satellite cell activation and promote the conversion of a quiescent satellite cell to a proliferating myoblast.

\section{Dynamic regulation of miRNAs during muscle regeneration}

MicroRNA-mediated gene silencing regulates alternative splicing $[52,53]$ as well as mRNA stability factors $[54,55]$. Moreover, miRNAs regulate stem cell fate determination $[28,30,31,56]$ suggesting a potential role for miRNAs in the transition of quiescent satellite cells to proliferating myoblasts. The low levels of RNA present in quiescent satellite cells combined with infrequent satellite cell abundance in uninjured muscle prevented successful unbiased screen for miRNAs. Therefore, we assessed whether genes involved in miRNA biogenesis and gene silencing including argonautes1-4 (Eif2c1-4), Dgcr8, and Dicer, as well as other genes associated with miRNA function, are expressed in quiescent satellite cell (Additional file 1, Additional file 2, Additional file 3, Additional file 4, Additional file 5, Additional file 6). Although present, Argonautes1-4 (Eif2c1-4), Dgcr8, and Dicer are not in the cohort of differentially expressed genes (Additional file 7), suggesting that major changes in miRNA processing do not occur during satellite cell activation.

To identify potential miRNAs involved in the transition of quiescent satellite cells to proliferating myoblasts, we applied miRNA target prediction algorithms to identify putative miRNAs regulating genes whose expression changes rapidly during the first $48 \mathrm{~h}$ post-muscle injury. Initially, we established a minimum gene expression value in freshly isolated satellite cells to reduce the 
Table 6 Genes used to predict candidate miRNAs

\begin{tabular}{|c|c|c|c|}
\hline Probe set ID & Gene symbol & Entrez gene & Fold change \\
\hline 1417654_at & Sdc4 & 20971 & 11.68 \\
\hline 1418282_x_at & Serpina $1 b$ & 20701 & 6.78 \\
\hline 1418510_s_at & Fbxo8 & 50753 & 4.74 \\
\hline 1419070_at & Cys1 & 12879 & 3.78 \\
\hline 1419302_at & Heyl & 56198 & 3.26 \\
\hline 1420930_s_at & Ctnnal1 & 54366 & 2.71 \\
\hline 1420980_at & Pak1 & 18479 & 3.13 \\
\hline 1422889_at & Pcdh18 & 73173 & 4.72 \\
\hline 1422892_s_at & $\mathrm{H} 2-\mathrm{Ea}$ & 14968 & 25.61 \\
\hline 1424559_at & Rpap2 & 231571 & 5.15 \\
\hline 1425336_x_at & $\mathrm{H} 2-\mathrm{K} 1$ & 14972 & 34.35 \\
\hline 1425609_at & Ncf1 & 17969 & 2.68 \\
\hline 1426981_at & Pcsk6 & 18553 & 3.38 \\
\hline 1427884_at & Col3a1 & 12825 & 12.29 \\
\hline 1429021_at & Epha4 & 13838 & 3.51 \\
\hline 1430764_at & 1700023F06Rik & 69441 & 3.12 \\
\hline 1433639_at & 5730593F17Rik & 215512 & 3.30 \\
\hline 1434105_at & Epm2aip1 & 77781 & 2.91 \\
\hline 1434267_at & Nek1 & 18004 & 2.90 \\
\hline 1434790_a_at & Lta4h & 16993 & 4.96 \\
\hline 1435603_at & Sned1 & 208777 & 3.12 \\
\hline 1437152_at & Mex3b & 108797 & 4.08 \\
\hline 1438532_at & Hmcn1 & 545370 & 6.09 \\
\hline 1438577_at & - & - & 5.66 \\
\hline 1439618_at & Pde10a & 23984 & 3.37 \\
\hline 1440237_at & Ercc4 & 50505 & 3.40 \\
\hline 1441958_s_at & Ager & 11596 & 7.06 \\
\hline 1442700_at & Pde4b & 18578 & 11.21 \\
\hline 1444409_at & Rph3al & 380714 & 3.92 \\
\hline 1444517_at & - & - & 3.13 \\
\hline 1447257_at & - & - & 2.45 \\
\hline 1447657_s_at & Synpo21 & 68760 & 3.00 \\
\hline 1449226_at & $\mathrm{Hicl}$ & 15248 & 3.11 \\
\hline 1449465_at & Reln & 19699 & 5.95 \\
\hline 1449619_s_at & Arhgap9 & 216445 & 3.20 \\
\hline 1451513_x_at & Serpina1a & 20700 & 4.62 \\
\hline 1452632_at & Aak1 & 269774 & 3.64 \\
\hline 1452896_at & Gtl3 & 14894 & 8.40 \\
\hline 1453114_at & Nol9 & 74035 & 2.30 \\
\hline 1453771_at & Gulp1 & 70676 & 5.06 \\
\hline 1454112_a_at & Cep27 & 66296 & 2.46 \\
\hline 1454433_at & 6330526H18Rik & 76174 & 2.95 \\
\hline 1454877_at & Sertad4 & 214791 & 6.96 \\
\hline 1455136_at & Atp1a2 & 98660 & 6.60 \\
\hline 1455188_at & Ephb1 & 270190 & 3.37 \\
\hline
\end{tabular}

Table 6 Genes used to predict candidate miRNAs (Continued)

\begin{tabular}{llll}
\hline 1457944_at & - & - & 16.23 \\
\hline 1459164_at & AU014678 & 101228 & 2.34
\end{tabular}

The relative expression data for genes that significantly change (ANOVA $P \leq 0.01, \geq$ two-fold change) in wild type satellite cells isolated from uninjured TA muscle or from the TA $48 \mathrm{~h}$ post-muscle injury and not in Sdc $4^{-/-}$satellite cells (ANOVA $P>0.9$ ) is represented as a $\log _{2}$ values. Gene identifiers are Probe set ID, representative gene symbol, and entrez gene ID. The fold change was calculated for changes occurring in the first $12 \mathrm{~h}$ postmuscle injury according to genotype.

cohort to 641 genes (ANOVA $P \leq 0.01$ ) that either increased or decreased by $\geq$ two-fold during the first $48 \mathrm{~h}$ following muscle injury. As gene expression levels did not change for 47 of these genes in $\mathrm{Sdc} 4^{-/-}$satellite cells (ANOVA $P \geq 0.9$ ), we chose these 47 genes to pursue as potential miRNA targets involved in satellite cell activation (Table 6). Candidate miRNAs were then computationally identified using two independent algorithms, one developed by the group of Deepak Srivastava (unpublished) and GeneAct (http://promoter. colorado.edu/geneact/) [57] (Figure 6A). The union of both algorithms identified 12 miRNA candidates with six, miR-16, miR-93, miR-106b, miR-107, miR-124, and miR-200b, being detected in cultured primary satellite cells or proliferating satellite cell derived MM14 cells by ribonuclease protection assay (Table 7). All six miRNAs present in primary myoblasts and MM14 cells were detectable in uninjured tibialis anterior muscle (Figure 6B).

We observed dramatic regulation of these six miRNAs following a muscle injury when compared to control, uninjured tibialis anterior muscle. Four of the identified miRNAs (miR-93, miR-107, miR-124, and miR-200b) changed expression levels by more than two-fold during the first 5 days following induced muscle injury (Figure 6B-F; Table 8). In the uninjured TA muscle, miR200b decreased three-fold by $12 \mathrm{~h}$ post-injury, while miR-93 and miR-124 increased significantly $12 \mathrm{~h}$ postmuscle injury (Figure 6B, C, F; Table 8). Within $48 \mathrm{~h}$ post-injury, the relative levels of miR-93, miR-107, and miR-124 had decreased levels well below those present in uninjured muscle and remained low at 5 days post-injury (Figure 6C-E). In contrast, miR-106b remained elevated following injury while miR-16 trended to slightly lower expression (Figure 6B-E). The rapid changes in miRNA relative expression and their presence in skeletal muscle suggest that these miRNAs may play important roles in the regeneration of skeletal muscle and validates our approach to identify such miRNAs.

\section{Relative expression of miRNAs in satellite cells following muscle injury}

We asked whether the six miRNAs that change expression during muscle regeneration are present in satellite cells, muscle tissue, or both. The relative expression 


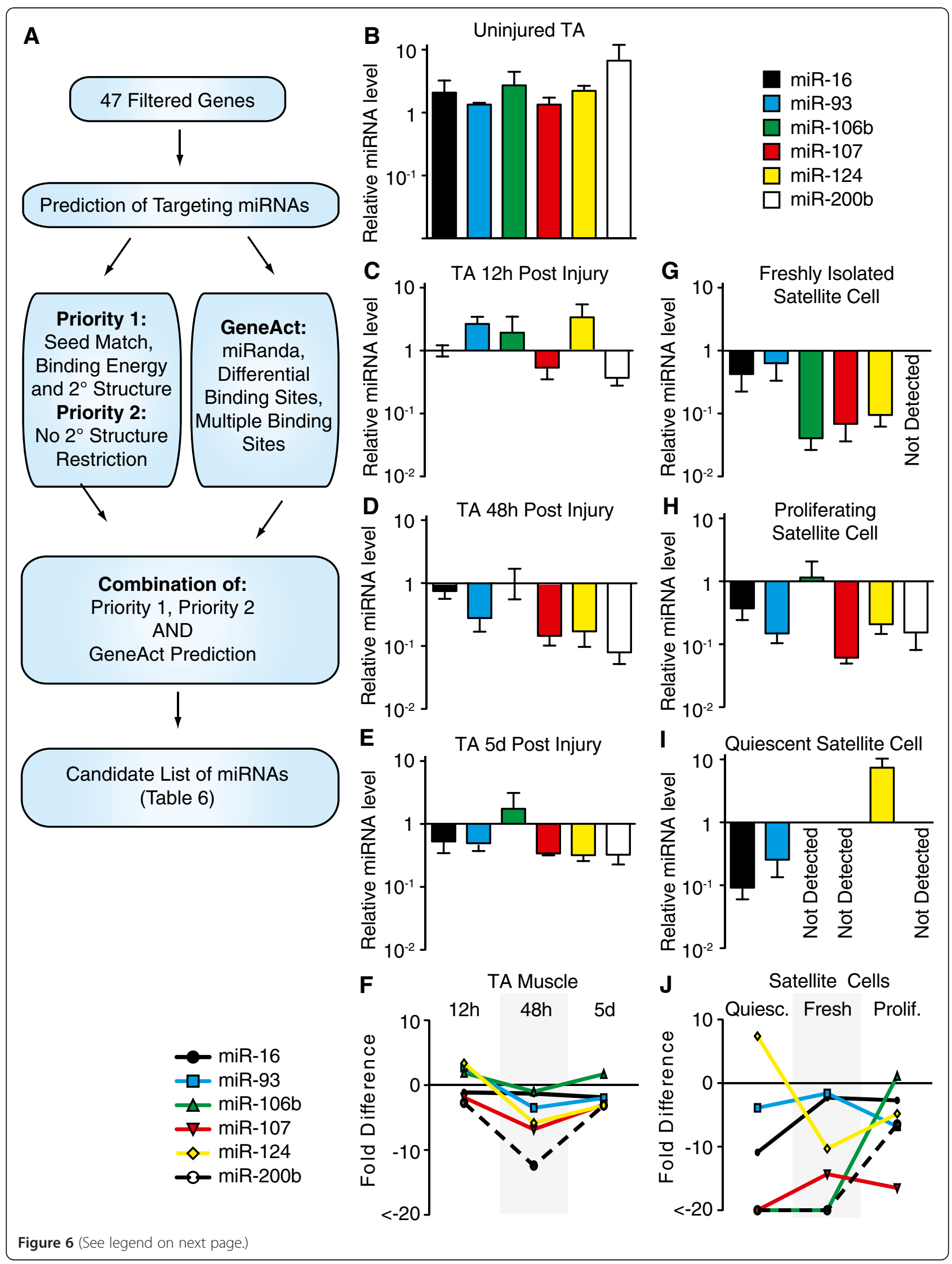


(See figure on previous page.)

Figure 6 Screening and characterization of candidate miRNAs with dynamic expression patterns during muscle regeneration.

A combinatorial screen was used to identify miRNAs from potential target genes that uniquely change expression in wild type satellite cells following a muscle injury. Gene expression changes of $\geq$ two-fold, $P \leq 0.01$ occurring in wild type satellite cells $48 \mathrm{~h}$ post-muscle injury compared to freshly isolated satellite cells that changed $\leq$ two.0-fold, $P \geq 0.9$ in syndecan- 4 null cells yielded 47 genes (Table 6) that were subjected to the flow schematic to identify potential miRNAs (A). The union from both algorithms yielded 12 candidate miRNAs, six of which were detectable by RNase protection assay in cultured satellite cells or the satellite cell derived MM14 cell line in growth or differentiation conditions (Table 7). These six miRNAs are expressed in uninjured skeletal muscle (B) and four of the six change expression dynamically during skeletal muscle regeneration at $12 \mathrm{~h}(\mathbf{C}, \mathbf{F}), 48 \mathrm{~h}(\mathbf{D}, \mathbf{F})$ and $5 \mathrm{~d}(\mathbf{E}, \mathbf{F})$ post-muscle injury. The same four micro RNAs (miR-16, miR-93, miR-106b, and miR-124) exhibit dynamic changes in relative expression when comparing activated satellite cells $(\mathbf{G}, \mathbf{J})$ to proliferating satellite cells $(\mathbf{H}, \mathbf{J})$ and quiescent satellite cells $(\mathbf{I}, \mathbf{J})$. All qPCR data was normalized to U6 RNA. miRNA levels in uninjured TA muscle were set to 1 (y-axis). Values above the y-axis indicate higher miRNA expression than in uninjured TA muscle and values below the $y$-axis indicate lower miRNA expression than in uninjured TA muscle (C-J). Graphs B-E and G-I are log scale and values are mean \pm SEM $(n=3)$. Graphs F and J are average fold difference as compared to relative expression in $B$.

levels for each miRNA in the uninjured tibialis anterior muscle was normalized to 1 and the relative levels in satellite cells isolated from uninjured muscle and in proliferating satellite cells isolated $48 \mathrm{~h}$ post-injury examined. Surprisingly, all six miRNAs were expressed at low to undetectable levels in freshly isolated satellite cells (Figure 6G). In proliferating satellite cells, all but miR106b were expressed at levels substantially lower than that found in the tibialis anterior muscle (Figure $6 \mathrm{H}$ ). Although MyoD protein is not detectable in freshly isolated satellite cells and they have not yet entered Sphase, freshly isolated satellite cells are not quiescent since the $\mathrm{p} 38 \alpha / \beta$ MAPK is activated [8]. Therefore, to identify miRNAs present in quiescent satellite cells, mice were injected with SB203580, a p38 $\alpha / \beta$ MAPK inhibitor, $1.5 \mathrm{~h}$ prior to satellite cell isolation (Hausburg et al., Submitted), and relative miRNA levels examined. Remarkably, we found that miR-124 was expressed 35-fold higher in quiescent satellite cells than in freshly isolated or proliferating satellite cells (Figure 6I, J; Table 8). Moreover, miR-124 was expressed at levels 10-fold greater in quiescent satellite cells than in uninjured skeletal muscle (compare Figure $6 \mathrm{I}$ and 6B, Figure 6); Table 8 ), suggesting that the primary source of miR-124 in uninjured muscle is the satellite cell population. In contrast to miR-124, miR-16 and miR-93 are present at low to undetectable levels in quiescent satellite cells and are induced in freshly isolated satellite cells (Figure 6G, I). The expression level of miR-16 is maintained in proliferating cells, while miR-93 declines and miR-106b is dramatically induced in proliferating satellite cells as compared to freshly isolated and quiescent satellite cells (Figure 6G-I).

miR-16, miR-106b, and miR-124 regulate satellite cell fate The changes in relative levels of miR-16, miR-93, miR106b, and miR-124 in satellite cells following a muscle injury suggests that these four miRNAs may play a role in the transition from a quiescent satellite cell to a proliferating myoblast. To test this idea, inhibitors for each miRNA were transfected into myofiberassociated satellite cells immediately following isolation and the cultures fixed and assayed at 3 days postisolation and 5 days post-isolation. The total number of Pax7+ cells transfected with the scrambled RNA control inhibitor declined two-fold between 3 and 5 days in culture, indicative of differentiation (Figure 7A, B). Between 3 and 5 days in culture, the Pax7+/MyoD+ decreased three-fold accompanied by the appearance of the Pax7+/MyoD- 'reserve' population (Figure 7C-F). In contrast, inhibition of miR-124 increased the percentage of Pax7+/MyoD- 'reserve' cells at 3 and 5 days of culture, as did inhibition of miR-106b (Figure 7A-F). Inhibition of miR-16 elevated the total number of Pax7+ cells at 5 days of culture and inhibition of miR-93 did not have any detectable effect (Figure 7-F). We further examined the role of miRNAs in satellite cell activation using Ingenuity ${ }^{\circledR}$ System's IPA and identified PTEN signaling and Cell Cycle Regulation by BTG Family Proteins as the top canonical pathway regulated by miR-16, miR-93, miR-106b, and miR-124 in the transition of a quiescent satellite cell to a proliferating myoblasts (Figure 8). Many predicted targets of miR-16 and the miR-93/106b family inhibit cell cycle progression and cell growth. These targets are downregulated during satellite cell activation, consistent with increased expression of miR-16, miR-93, and miR$106 \mathrm{~b}$ in proliferating satellite cells as compared to quiescent satellite cells (Figure 8). Conversely, predicted target genes of miR-124 promote cell cycle progression and are upregulated during satellite cell activation when miR-124 is downregulated (Figure 8). These data demonstrate that a number of miRNAs regulate satellite cell fate following a muscle injury and support the idea that posttranscriptional regulation of RNA plays a critical role in satellite cell activation and maintenance of satellite cell quiescence. 
Table 7 Six of twelve predicted miRNAs are expressed in satellite cells

\begin{tabular}{lll}
\hline miRNA & Rationale & Detected in SCs \\
\hline miR-16 & Priority 2 and GeneAct & + \\
\hline miR-26a/b & Priority 1 and GeneAct & $\mathrm{ND}$ \\
\hline miR-30a & Priority 1,2 and GeneAct & - \\
\hline miR-93 & Priority 1 and GeneAct & + \\
\hline miR-106b & Priority 1 and GeneAct & + \\
\hline miR-107 & Priority 2 and GeneAct & + \\
\hline miR-124 & Priority 1 and GeneAct & + \\
\hline miR-130a & Priority 1 and GeneAct & - \\
\hline miR-132 & Priority 1 and GeneAct & - \\
\hline miR-200b & Priority 1 and GeneAct & + \\
\hline miR-320 & Priority 1 and GeneAct & - \\
\hline miR-424 & Priority 1 and GeneAct & - \\
\hline
\end{tabular}

We predicted 12 candidate miRNAs from 47 genes identified as only expressed in satellite cells or only expressed in myoblasts. miR-16, miR-93, miR-106b, miR-107, miR-124, and miR-200b are detected in satellite cells by RNase protection assay in either primary satellite cells or in the satellite cell derived MM14 cell line.

\section{Discussion}

The low cytoplasmic to nuclear ratio, low organelle number, and mitotic quiescence of resident satellite cells $[12,13]$ lead to the speculation that metabolic activity in these cells is low. Indeed, quiescent satellite cells with high levels of Pax7 express reduced levels of mitochondrial genes [58]. Moreover, the delay to the first cell cycle division (Troy et al. ) $^{\mathrm{a}}$ coupled with the dramatic increase in cell size and mobility $[36,44]$ suggests that satellite cell activation and cell cycle entry would require transcriptional induction of a large cohort of genes similar to that observed in serum stimulated fibroblasts [59]. However, we and others have postulated that quiescent satellite cells are poised for activation awaiting a critical signaling event $[8,14]$. The data presented here further support this hypothesis and provide the first direct comparison of quiescent satellite cells with activated satellite cells and proliferating myoblasts derived from uninjured and injured skeletal muscle, respectively. The prior analyses performed compared freshly isolated satellite cells with satellite cells isolated from dystrophic mice [14] or cultured cells [14,34] and are expected to identify gene expression changes associated with a diseased environment or a culture environment, respectively. Since the most significant reductions in gene expression occur within the first $12 \mathrm{~h}$ post-muscle injury, the metabolic and signaling events in a quiescent satellite cell are thus predicted to be divergent from those of a proliferating myoblast. Moreover, these data suggest that comparisons of freshly isolated satellite cells with proliferating myoblasts may not identify critical regulatory mechanisms involved in satellite cell activation $[14,34]$.

Here, we used computational methods to initially identify that RNA post-transcriptional mechanisms are likely to maintain the quiescent satellite cell phenotype and to promote the conversion of the quiescent satellite cell to a transit-amplifying myoblast. Recent studies indicate that RNA post-transcriptional mechanisms, specifically alternative splicing, mRNA stability, and miRNA-mediated gene silencing, regulate stem cell pluripotency and progression through differentiation [17-20]. As satellite cells are an adult stem cell population, similar mechanisms may mediate the transition from quiescence to a population of proliferating myoblasts. We found that splicing factors may play roles in regulating the transition of satellite cells from quiescence to proliferating myoblasts. Consistent with these observations, the relative molar ratios of splicing factors guide alternative splicing [60] and these factors often function combinatorially to direct the expression of different mRNA splice variants [61]. Together with published data, our observations of dynamic splicing factor expression in satellite cells following muscle injury suggests that unique cohorts of mRNA species regulate the conversion of quiescent adult stem cells to the committed proliferating myoblast.

In addition to splicing factors, we found that mRNA binding proteins regulating mRNA stabilization and mRNA decay are preferentially upregulated in satellite cells following muscle injury. Indeed, the AU-rich element (ARE) binding protein HuR (Elavl1) is reported to stabilize MyoD and myogenin mRNA in skeletal muscle cell lines derived from satellite cells $[62,63]$ potentially participating in satellite cell activation and commitment

Table 8 Fold difference of candidate miRNAs as compared to levels in resting muscle

\begin{tabular}{|c|c|c|c|c|c|c|}
\hline & miR-16 & miR-93 & miR-106b & $\operatorname{miR}-107$ & $\operatorname{miR}-124$ & miR-200b \\
\hline $12 \mathrm{~h} \mathrm{PI}$ & -1.1 & 2.7 & 1.9 & -1.9 & 3.4 & -2.7 \\
\hline $48 \mathrm{~h} \mathrm{PI}$ & -1.3 & -3.5 & $\mathrm{NC}$ & -6.8 & -5.8 & -12.4 \\
\hline $5 \mathrm{dPl}$ & -1.9 & -2.0 & 1.7 & -3.0 & -3.1 & -3.1 \\
\hline Quiescent satellite cell & -10.9 & -3.9 & ND & ND & 7.4 & ND \\
\hline Freshly isolated satellite cell & -2.3 & -1.6 & -24.3 & -14.3 & -10.3 & -1418.2 \\
\hline Proliferating satellite cell & -2.7 & -6.8 & 1.1 & -16.5 & -4.8 & -6.5 \\
\hline
\end{tabular}

Fold difference of miRNA expression as compared to resting muscle where positive values are higher expression and negative values are lower expression. NC, no change; ND, not detected. 


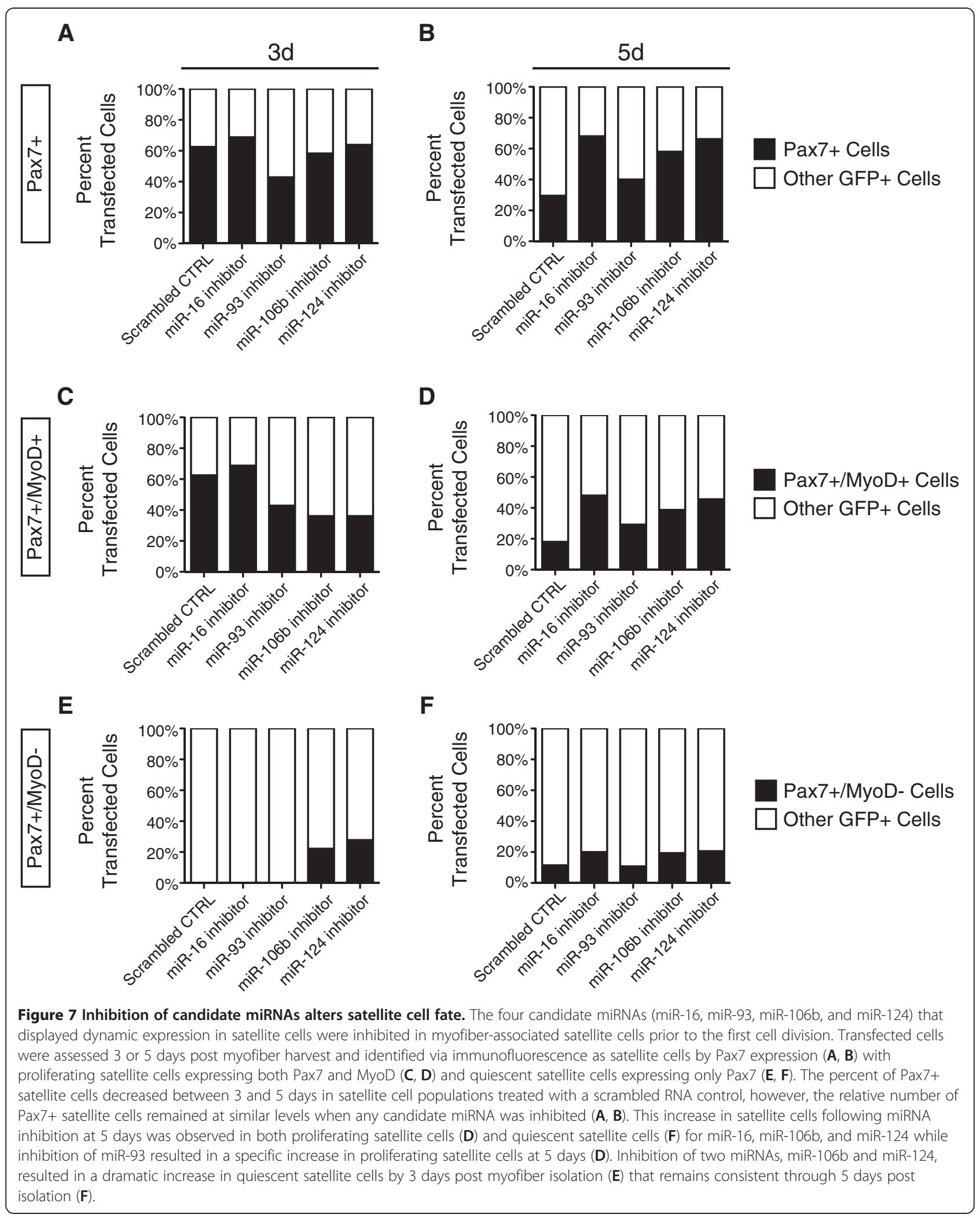




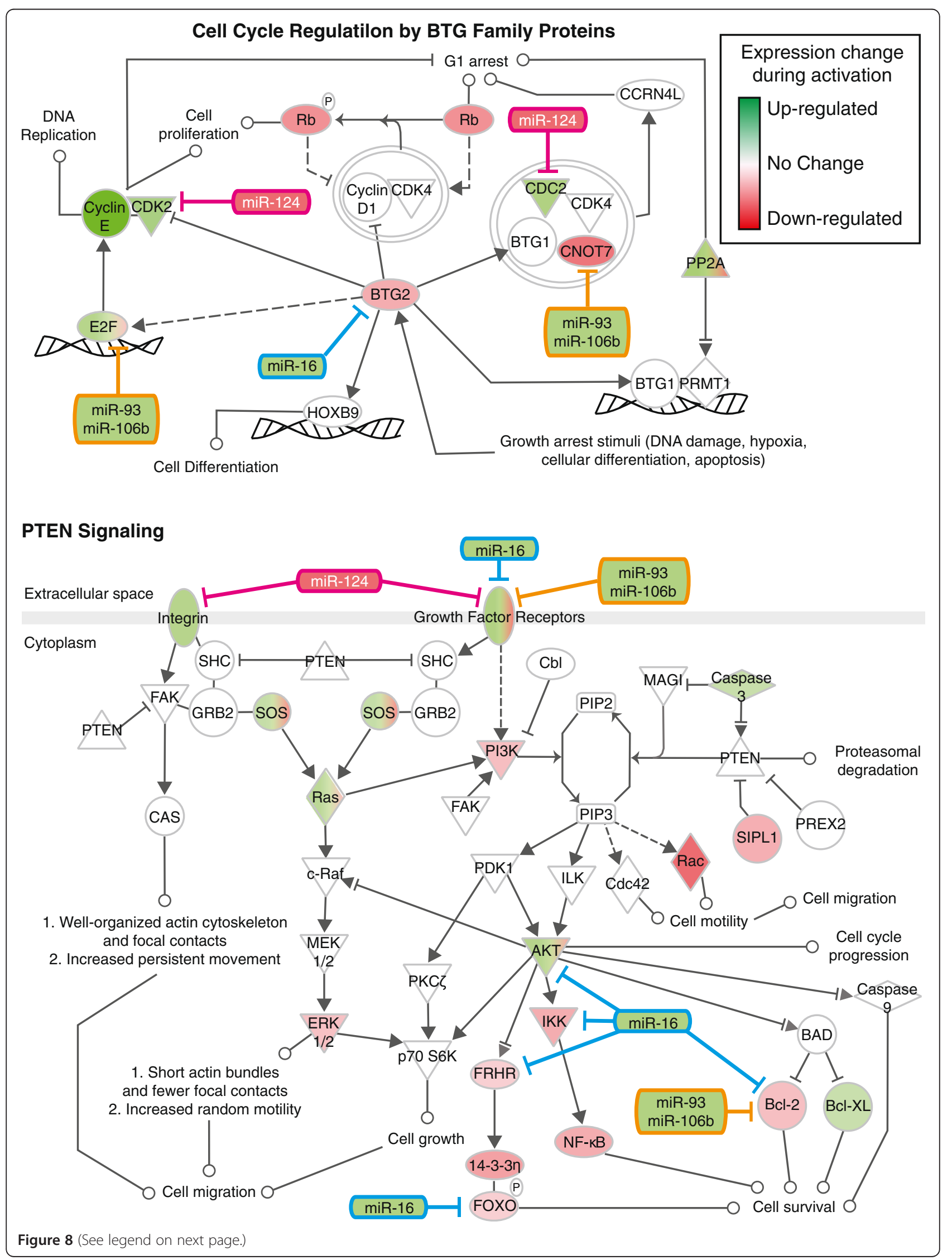


(See figure on previous page.)

Figure 8 Candidate miRNAs target genes involved in cell growth, survival, migration, and cell cycle progression. The predicted target genes of miR-16, miR-93, miR-106b, and miR-124 were identified using Ingenuity ${ }^{\circledR}$ Systems (www.ingenuity.com). PTEN Signaling and Cell Cycle Regulation by BTG Family Proteins emerged as the top ranked canonical pathway regulated during satellite cell activation. The pathways and relative expression changes occurring during satellite cell activation are depicted. Note that the miRNAs have opposite expression profiles of their respective target mRNAs. Red indicates mRNAs downregulated and green indicates mRNAs upregulated with the intensity of red or green indicating increasing or decreasing fold change, respectively. The data compare mRNAs unique to wild type satellite cells isolated $12 \mathrm{~h}$ post-injury to satellite cells isolated from uninjured skeletal muscle.

to myogenesis. Elavl1 is one of the most significantly upregulated RNA binding genes in satellite cells within $12 \mathrm{~h}$ of muscle injury (See Figure 5C; Additional file 8) and corresponds to MyoD expression. Interestingly, the ARE-binding proteins, tristetraprolin (Zfp36) and family members Zfp36l1 and Zfp3612, decrease dramatically during the conversion from quiescence to activated satellite cells within the first $12 \mathrm{~h}$ post-muscle injury (See Figure 5D; Additional file 8). However, tristetraprolin and HuR have opposing functions as they counterregulate expression of the same mRNAs [64,65] and may act as an agonist-antagonist pair for many genes that promote commitment to myogenesis. In agreement with these data, we have demonstrated that the Zfp36 family directly targets MyoD mRNA and functions to regulate satellite cell fate during satellite cell activation and self-renewal (Hausburg et al., Submitted).

A recent report identifies miR-489 as an important miRNA maintaining satellite cell quiescence [32] suggesting that miRNA-mediated gene silencing functions in the transition of a quiescent satellite cell to a proliferating myoblast. We identified a cohort of genes that significantly change expression in satellite cells within the first $48 \mathrm{~h}$ following muscle injury to computationally predict cognate miRNAs that may regulate these targets with two independent prediction algorithms. Six miRNAs not previously reported in skeletal muscle were selected for further analysis and all six were observed to be dynamically regulated in relative levels during induced muscle injury. Moreover, four of the six miRNAs were expressed in satellite cells (miR-16, miR-93, miR-106b, and miR-124), while two were likely present only in differentiated muscle (miR-107 and miR-200b). Comparing relative levels in muscle tissue and satellite cells revealed that miR-124 is likely only expressed in satellite cells, while miR-16, miR93, and miR-106b are most likely expressed in satellite cells and in differentiated muscle fibers. Pathways predicted to be targeted by these miRNAs include cell cycle progression as well as PTEN signaling, which is involved in stem cell self-renewal [66] and muscle regeneration [67].

To directly test whether these four miRNAs regulate satellite cell behavior, we transfected inhibitors for each miRNA into myofiber-associated satellite cells shortly after isolation and examined the effects on satellite cell fate at 3 and 5 days post-myofiber isolation. Inhibition of two miRNAs, miR-106b and miR-124, increased the relative number of progenitor or 'reserve' satellite cells (Pax7 +/MyoD-) relative to a control, suggesting that these miRNAs participate in the regulation of satellite cell fate and satellite cell self-renewal. In contrast, miR-16 enhanced the relative numbers of Pax7+ cells but did not appear to alter the percentage of Pax $7+/$ MyoD + myoblasts or Pax 7 +/MyoD- 'reserve' cells relative to a scrambled control. Of the four miRNAs tested, the loss of miR-93 elicited no detectable changes in the numbers of 'reserve' Pax7 +/MyoD- satellite cells and Pax7+/MyoD + satellite cells suggesting functions in cellular processes other than cell fate determination.

\section{Conclusions}

We believe that RNA post-transcriptional regulation plays a critical role in the transition of a quiescent satellite cell to a transit-amplifying myoblast. At each time point we examined, including quiescent satellite cells (freshly isolated in the presence of a $\mathrm{p} 38 \alpha / \beta$ MAPK inhibitor), activated satellite cells (12 h post-muscle injury), and proliferating myoblasts (48 $\mathrm{h}$ post-muscle injury), we found extensive changes in genes involved in posttranscriptional RNA regulation, including mRNA splicing, mRNA stability, and miRNA-mediated gene silencing. We conclude that satellite cell quiescence is actively maintained via combinatorial contributions primarily mediated through post transcriptional mRNA regulation and identified four miRNAs that likely play a role in the conversion of quiescent satellite cells to proliferating myoblasts.

\section{Endnotes}

Following submission of our manuscript, the following was published demonstrating post-transcriptional regulation of myf-5 during satellite cells activation. Crist CG, Montarras D, Buckingham M (2012) Muscle Satellite Cells Are Primed for Myogenesis but Maintain Quiescence with Sequestration of Myf5 mRNA Targeted by microRNA-31 in mRNP Granules. Cell Stem Cell 11: 118-126.

\section{Additional files}

Additional file 1: CEL files of wild type satellite cells isolated from uninjured muscle. Raw expression data for three replicates of satellite 
cells isolated from wild type uninjured TA muscles. *. CEL files can be opened with any microarray analysis software including the Affymetrix Expression Console Software (http://www.affymetrix.com/estore/browse/ level_seven_software_products_only.jsp?

productld $=131414 \&$ categoryld $=35623 \&$ productName=AffymetrixExpression-Console-Software\#1_1).

Additional file 2: CEL files of wild type satellite cells isolated $12 \mathrm{~h}$ post-injury. Raw expression data for three replicates of satellite cells isolated from wild type TA muscles $12 \mathrm{~h}$ post-injury. *. CEL files can be opened with any microarray analysis software including the Affymetrix Expression Console Software (http://www.affymetrix.com/estore/browse/ level_seven_software_products_only.jsp?

productld $=131414 \&$ categoryld $=35623 \&$ productName $=$ Affymetrix -

Expression-Console-Software\#1_1).

Additional file 3: CEL files of wild type satellite cells isolated $48 \mathrm{~h}$ post-injury. Raw expression data for three replicates of satellite cells isolated from wild type TA muscles $12 \mathrm{~h}$ post-injury. *. CEL files can be opened with any microarray analysis software including the Affymetrix Expression Console Software (http://www.affymetrix.com/estore/browse/ level_seven_software_products_only.jsp?

productld $=131414 \&$ categoryld $=35623 \&$ productName=AffymetrixExpression-Console-Software\#1_1).

Additional file 4: CEL files of syndecan- $4^{-/-}$satellite cells isolated from uninjured muscle. Raw expression data for three replicates of satellite cells isolated from syndecan- $4^{-/-}$uninjured TA muscles. *. CEL files can be opened with any microarray analysis software including the Affymetrix Expression Console Software (http://www.affymetrix.com/ estore/browse/level_seven_software_products_only.jsp? productld $=131414 \&$ categoryld $=35623 \&$ product Name=AffymetrixExpression-Console-Software\#1_1).

\section{Additional file 5: CEL files of syndecan- $4^{-/-}$satellite cells isolated}

$12 \mathrm{~h}$ post-injury. Raw expression data for three replicates of satellite cells isolated from syndecan-4-4- TA muscles $12 \mathrm{~h}$ post-injury. *. CEL files can be opened with any microarray analysis software including the Affymetrix Expression Console Software (http://www.affymetrix.com/ estore/browse/level_seven_software_products_only.jsp? productld $=131414 \&$ categoryld $=35623 \&$ productName $=$ Affymetrix Expression-Console-Software\#1_1).

\section{Additional file 6: CEL files of syndecan- $4^{-/-}$satellite cells isolated} $48 \mathrm{~h}$ post-injury. Raw expression data for three replicates of satellite cells isolated from syndecan-4/- TA muscles $12 \mathrm{~h}$ post-injury. *. CEL files can be opened with any microarray analysis software including the Affymetrix Expression Console Software (http://www.affymetrix.com/ estore/browse/level_seven_software_products_only.jsp? productld=131414\&categoryld=35623\&productName=AffymetrixExpression-Console-Software\#1_1).

Additional file 7: Satellite cell activation gene expression profile. Excel spreadsheet $\left({ }^{*} . x \mid s x\right)$ with columns for probe set ID, $\log _{2}$ expression data, ANOVA $P$ value, fold change, and gene ID for unique genes that significantly change (ANOVA $P \leq 0.01, \geq$ two-fold change) in WT and not in $\mathrm{Sdc}^{-/-}$satellite cells $12 \mathrm{~h}$ after $\mathrm{BaCl}_{2}$-induced injury. The ANOVA $P$ value and fold change was calculated for changes occurring in the first $12 \mathrm{~h}$ post-muscle injury according to genotype.

Additional file 8: Molecular Function: RNA Binding genes regulated during satellite cell activation. Excel spreadsheet $\left({ }^{*} . x \mid s x\right)$ of RNA binding proteins from Additional file 7 with gene identifiers of Probe set $I D$, representative gene symbol, and entrez gene ID. The relative expression data for genes that significantly change (ANOVA

$P \leq 0.01, \geq$ two-fold change) in wild type and in Sdc ${ }^{-/-}$satellite cells isolated from uninjured TA muscle or from the TA $12 \mathrm{~h}$ post-muscle injury is represented as a $\log _{2}$.

\section{Abbreviations}

ARE: AU-rich element; GO: gene ontology; PI: post injury; TA: tibialis anterior: UI: uninjured; WT: wild type.

\section{Competing interests}

The authors do not have any competing interests.

\section{Authors' contributions}

NHF carried out bioinformatic analyses of the microarray data, designed and carried out the miRNA studies, and drafted the manuscript. MH carried out qRT-PCR for mRNA expression and many of the bioinformatic analyses of the microarray data. NDB carried out qRT-PCR for miRNA expression. CP carried out qRT-PCR for mRNA expression. DS carried out miRNA prediction. DDWC carried out satellite cell isolation and hybridization for the microarray. BBO conceived of the study, participated in its design and coordination, and helped to draft the manuscript. All authors read and approved the final manuscript.

\section{Acknowledgements}

We thank Tiffany Antwine for technical assistance and members of the Olwin laboratory for critical discussion of this manuscript.

The project described was supported by the National Institutes of Health grant AR049446 to B. B. Olwin, a grant from the Muscular Dystrophy Association to B.B. Olwin and a Muscular Dystrophy Association Development Grant to D.D.W. Cornelison.

\section{Author details}

${ }^{1}$ Department of Molecular, Cellular, and Developmental Biology, University of Colorado, Boulder, CO 80309, USA. ²aboratory of Signal Transduction, National Institute of Environmental Health Sciences, Research Triangle Park, Triangle Park, NC 22709, USA. ${ }^{3}$ Gladstone Institute of Cardiovascular Disease, University of San Francisco, San Francisco, CA 94158, USA. ${ }^{4}$ Biological Sciences and Bond Life Sciences Center, University of Missouri, Columbia, MO 65211, USA

Received: 8 May 2012 Accepted: 15 August 2012 Published: 9 October 2012

\section{References}

1. Lepper C, Partridge TA, Fan C-M: An absolute requirement for Pax7positive satellite cells in acute injury-induced skeletal muscle regeneration. Development 2011, 138:3639-3646.

2. Murphy MM, Lawson JA, Mathew SJ, Hutcheson DA, Kardon G: Satellite cells, connective tissue fibroblasts and their interactions are crucial for muscle regeneration. Development 2011, 138:3625-3637.

3. Sambasivan $R$, Yao R, Kissenpfennig A, Van Wittenberghe L, Paldi A, Gayraud-Morel B, Guenou H, Malissen B, Tajbakhsh S, Galy A: Pax7expressing satellite cells are indispensable for adult skeletal muscle regeneration. Development 2011, 138:3647-3656.

4. Allen RE, Sheehan SM, Taylor RG, Kendall TL, Rice GM: Hepatocyte growth factor activates quiescent skeletal muscle satellite cells in vitro. J Cell Physiol 1995, 165:307-312.

5. Tatsumi R, Anderson JE, Nevoret CJ, Halevy O, Allen RE: HGF/SF is present in normal adult skeletal muscle and is capable of activating satellite cells. Dev Biol 1998, 194:114-128.

6. Anderson JE: A role for nitric oxide in muscle repair: nitric oxidemediated activation of muscle satellite cells. Mol Biol Cell 2000, 11:1859-1874.

7. Li YP: TNF-alpha is a mitogen in skeletal muscle. Am J Physiol Cell Physiol 2003, 285:C370-C376.

8. Jones NC, Tyner KJ, Nibarger L, Stanley HM, Cornelison DD, Fedorov YV Olwin BB: The p38alpha/beta MAPK functions as a molecular switch to activate the quiescent satellite cell. J Cell Biol 2005, 169:105-116.

9. Troy A, Cadwallader AB, Fedorov Y, Tyner K, Tanaka KK, Olwin BB: Coordination of satellite cell activation and self-renewal by Par-ComplexDependent Asymmetric Activation of P38a/ß MAPK. Cell Stem Cell 2012, 11:541-553.

10. Zhang K, Sha J, Harter ML: Activation of Cdc 6 by MyoD is associated with the expansion of quiescent myogenic satellite cells. J Cell Biol 2010, 188:39-48.

11. Kuang S, Kuroda K, Le Grand F, Rudnicki MA: Asymmetric self-renewal and commitment of satellite stem cells in muscle. Cell 2007, 129:999-1010.

12. Le Grand F, Jones AE, Seale V, Scimè A, Rudnicki MA: Wnt7a activates the planar cell polarity pathway to drive the symmetric expansion of satellite stem cells. Cell Stem Cell 2009, 4:535-547. 
13. Mauro A: Satellite cell of skeletal muscle fibers. J Biophys Biochem Cytol 1961, 9:493-495.

14. Ishikawa H: Electron microscopic observations of satellite cells with special reference to the development of mammalian skeletal muscles. Z Anat Entwicklungsgesch 1966, 125:43-63.

15. Pallafacchina G, François S, Regnault B, Czarny B, Dive V, Cumano A, Montarras D, Buckingham M: An adult tissue-specific stem cell in its niche: a gene profiling analysis of in vivo quiescent and activated muscle satellite cells. Stem Cell Res 2010, 4:77-91.

16. Lemons JM, Feng XJ, Bennett BD, Legesse-Miller A, Johnson EL, Raitman I, Pollina EA, Rabitz HA, Rabinowitz JD, Coller HA: Quiescent fibroblasts exhibit high metabolic activity. PLoS Biol 2010, 8:e1000514

17. Pritsker M, Doniger TT, Kramer LC, Westcot SE, Lemischka IR: Diversification of stem cell molecular repertoire by alternative splicing. Proc Natl Acad Sci U S A 2005, 102:14290-14295.

18. Atlasi Y, Mowla SJ, Ziaee SA, Gokhale PJ, Andrews PW: OCT4 spliced variants are differentially expressed in human pluripotent and nonpluripotent cells. Stem Cells 2008, 26:3068-3074.

19. Calvanese V, Lara E, Suárez-Alvarez B, Abu Dawud R, Vázquez-Chantada M, Martínez-Chantar ML, Embade N, López-Nieva P, Horrillo A, Hmadcha A, Soria B, Piazzolla D, Herranz D, Serrano M, Mato JM, Andrews PW, LópezLarrea C, Esteller M, Fraga MF: Sirtuin 1 regulation of developmental genes during differentiation of stem cells. Proc Natl Acad Sci U S A 2010, 107:13736-13741.

20. Rao S, Zhen S, Roumiantsev S, McDonald LT, Yuan GC, Orkin SH: Differential roles of Sall4 isoforms in embryonic stem cell pluripotency. Mol Cell Biol 2010, 30:5364-5380.

21. Gabut M, Samavarchi-Tehrani P, Wang X, Slobodeniuc V, O'Hanlon D, Sung HK, Alvarez M, Talukder S, Pan Q, Mazzoni EO, Nedelec S, Wichterle H, Woltjen K, Hughes TR, Zandstra PW, Nagy A, Wrana JL, Blencowe BJ: An alternative splicing switch regulates embryonic stem cell pluripotency and reprogramming. Cell 2011, 147:132-146.

22. Chen JF, Mandel EM, Thomson JM, Wu Q, Callis TE, Hammond SM, Conlon FL, Wang DZ: The role of microRNA-1 and microRNA-133 in skeletal muscle proliferation and differentiation. Nat Genet 2006, 38:228-233.

23. Kim HK, Lee YS, Sivaprasad U, Malhotra A, Dutta A: Muscle-specific microRNA miR-206 promotes muscle differentiation. J Cell Biol 2006, 174:677-687.

24. Flynt AS, Li N, Thatcher EJ, Solnica-Krezel L, Patton JG: Zebrafish miR-214 modulates Hedgehog signaling to specify muscle cell fate. Nat Genet 2007, 39:259-263.

25. Lee RC, Feinbaum RL, Ambros V: The $C$. elegans heterochronic gene lin- 4 encodes small RNAs with antisense complementarity to lin-14. Cell 1993 75:843-854

26. Lee RC, Ambros V: An extensive class of small RNAs in Caenorhabditis elegans. Science 2001, 294:862-864

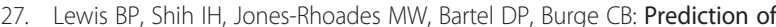
mammalian microRNA targets. Cell 2003, 115:787-798.

28. Lewis BP, Burge CB, Bartel DP: Conserved seed pairing, often flanked by adenosines, indicates that thousands of human genes are microRNA targets. Cell 2005, 120:15-20.

29. Chen CZ, Li L, Lodish HF, Bartel DP: MicroRNAs modulate hematopoietic lineage differentiation. Science 2004, 303:83-86.

30. Johnston RJ, Chang S, Etchberger JF, Ortiz CO, Hobert O: MicroRNAs acting in a double-negative feedback loop to control a neuronal cell fate decision. Proc Natl Acad Sci U S A 2005, 102:12449-12454.

31. Georgantas RW, Hildreth R, Morisot S, Alder J, Liu CG, Heimfeld S, Calin GA, Croce CM, Civin Cl: CD34+ hematopoietic stem-progenitor cell microRNA expression and function: a circuit diagram of differentiation control. ProC Natl Acad Sci U S A 2007, 104:2750-2755.

32. Ivey KN, Muth A, Arnold J, King FW, Yeh RF, Fish JE, Hsiao EC, Schwartz RJ, Conklin BR, Bernstein HS, Srivastava D: MicroRNA Regulation of Cell Lineages in Mouse and Human Embryonic Stem Cells. Cell Stem Cell 2008, 2:219-229.

33. Cheung TH, Quach NL, Charville GW, Liu L, Park L, Edalati A, Yoo B, Hoang $P$, Rando TA: Maintenance of muscle stem-cell quiescence by microRNA489. Nature 2012, 482:524-528.

34. Boutet SC, Cheung TH, Quach NL, Liu L, Prescott SL, Edalati A, lori K, Rando TA: Alternative polyadenylation mediates microRNA regulation of muscle stem cell function. Cell Stem Cell 2012, 10:327-336.
35. Fukada S, Uezumi A, Ikemoto M, Masuda S, Segawa M, Tanimura N, Yamamoto H, Miyagoe-Suzuki Y, Takeda S: Molecular signature of quiescent satellite cells in adult skeletal muscle. Stem Cells 2007 25:2448-2459.

36. Echtermeyer F, Streit M, Wilcox-Adelman S, Saoncella S, Denhez F, Detmar $M$, Goetinck P: Delayed wound repair and impaired angiogenesis in mice lacking syndecan-4. J Clin Invest 2001, 107:R9-R14.

37. Cornelison DD, Wilcox-Adelman SA, Goetinck PF, Rauvala H, Rapraeger AC, Olwin BB: Essential and separable roles for Syndecan-3 and Syndecan-4 in skeletal muscle development and regeneration. Genes Dev 2004, 18:2231-2236

38. Hall JK, Banks GB, Chamberlain JS, Olwin BB: Prevention of muscle aging by myofiber-associated satellite cell transplantation. Sci Trans/ Med 2010 2:57-83.

39. Cornelison DD, Filla MS, Stanley HM, Rapraeger AC, Olwin BB: Syndecan-3 and syndecan- 4 specifically mark skeletal muscle satellite cells and are implicated in satellite cell maintenance and muscle regeneration. Dev Biol 2001, 239:79-94

40. da Huang W, Sherman BT, Lempicki RA: Systematic and integrative analysis of large gene lists using DAVID bioinformatics resources. Nat Protoc 2009, 4:44-57.

41. da Huang W, Sherman BT, Lempicki RA: Bioinformatics enrichment tools: paths toward the comprehensive functional analysis of large gene lists. Nucleic Acids Res 2009, 37:1-13.

42. Prifti $\mathrm{E}$, Zucker JD, Clement $\mathrm{K}$, Henegar C: FunNet: an integrative tool for exploring transcriptional interactions. Bioinformatics 2008, 24:2636-2638.

43. Prifti E, Zucker JD, Clément K, Henegar C: Interactional and functional centrality in transcriptional co-expression networks. Bioinformatics 2010, 26:3083-3089.

44. Antonov AV, Schmidt T, Wang Y, Mewes HW: ProfCom: a web tool for profiling the complex functionality of gene groups identified from highthroughput data. Nucleic Acids Res 2008, 36:W347-W351.

45. Stark DA, Karvas RM, Siegel AL, Cornelison DD: Eph/ephrin interactions modulate muscle satellite cell motility and patterning. Development 2011, 138:5279-5289.

46. Boutz PL, Chawla G, Stoilov P, Black DL: MicroRNAs regulate the expression of the alternative splicing factor nPTB during muscle development. Genes Dev 2007, 21:71-84.

47. Smith RA, Meade K, Pickford CE, Holley RJ, Merry CL: Glycosaminoglycans as regulators of stem cell differentiation. Biochem Soc Trans 2011 , 39:383-387.

48. Mourelatos Z, Dostie J, Paushkin S, Sharma A, Charroux B, Abel L, Rappsilber J, Mann M: Dreyfuss G: miRNPs: a novel class of ribonucleoproteins containing numerous microRNAs. Genes Dev 2002, 16:720-728.

49. Heinrichs A: MicroRNAs get a boost. Nat Rev Mol Cell Biol 2009, 10:302.

50. Johnson SM, Grosshans H, Shingara J, Byrom M, Jarvis R, Cheng A, Labourier E, Reinert KL, Brown D, Slack FJ: RAS is regulated by the let-7 microRNA family. Cell 2005, 120:635-647.

51. Cheung $T H$, Kwan $Y L$, Hamady M, Liu X: Unraveling transcriptional control and cis-regulatory codes using the software suite GeneACT. Genome Biol 2006, 7:R97.

52. Rocheteau P, Gayraud-Morel B, Siegl-Cachedenier I, Blasco MA, Tajbakhsh S: A subpopulation of adult skeletal muscle stem cells retains all template DNA strands after cell division. Cell 2012, 148:112-125.

53. Kops GJ, Medema RH, Glassford J, Essers MA, Dijkers PF, Coffer PJ, Lam EW, Burgering BM: Control of cell cycle exit and entry by protein kinase Bregulated forkhead transcription factors. Mol Cell Biol 2002, 22:2025-2036.

54. Cáceres JF, Stamm S, Helfman DM, Krainer AR: Regulation of alternative splicing in vivo by overexpression of antagonistic splicing factors. Science 1994, 265:1706-1709.

55. Barberan-Soler S, Medina P, Estella J, Williams J, Zahler AM: Co-regulation of alternative splicing by diverse splicing factors in Caenorhabditis elegans. Nucleic Acids Res 2011, 39:666-674.

56. Figueroa A, Cuadrado A, Fan J, Atasoy U, Muscat GE, Muñoz-Canoves $P$, Gorospe M, Muñoz A: Role of HuR in skeletal myogenesis through coordinate regulation of muscle differentiation genes. Mol Cell Biol 2003, 23:4991-5004

57. van der Giessen K, Di-Marco S, Clair E, Gallouzi IE: RNAi-mediated HuR depletion leads to the inhibition of muscle cell differentiation. J Biol Chem 2003, 278:47119-47128. 
58. Young LE, Sanduja S, Bemis-Standoli K, Pena EA, Price RL, Dixon DA: The mRNA binding proteins HuR and tristetraprolin regulate cyclooxygenase 2 expression during colon carcinogenesis. Gastroenterology 2009, 136:1669-1679.

59. Chen F, Shyu AB, Shneider BL: Hu antigen R and tristetraprolin: counterregulators of rat apical sodium-dependent bile acid transporter by way of effects on messenger RNA stability. Hepatology 2011, 54:1371-1378.

60. Groszer M, Erickson R, Scripture-Adams DD, Dougherty JD, Le Belle J, Zack JA, Geschwind DH, Liu X, Kornblum HI, Wu H: PTEN negatively regulates neural stem cell self-renewal by modulating G0-G1 cell cycle entry. Proc Natl Acad Sci U S A 2006, 103:111-116.

61. Hu Z, Wang H, Lee IH, Modi S, Wang X, Du J, Mitch WE: PTEN inhibition improves muscle regeneration in mice fed a high-fat diet. Diabetes 2010, 59:1312-1320.

62. Kimura E, Hidaka K, Kida Y, Morisaki H, Shirai M, Araki K, Suzuki M, Yamamura KI, Morisaki T: Serine-arginine-rich nuclear protein Luc7l regulates myogenesis in mice. Gene 2004, 341:41-47.

63. Yang $T$, Adamson $T E$, Resnick JL, Leff $S$, Wevrick R, Francke $U$, Jenkins $N A$, Copeland NG, Brannan Cl: A mouse model for Prader-Willi syndrome imprinting-centre mutations. Nat Genet 1998, 19:25-31.

64. Ito T, Saso K, Arimitsu N, Sekimizu K: Defective FESTA/EAF2-mediated transcriptional activation in S-II-deficient embryonic stem cells. Biochem Biophys Res Commun 2007, 363:603-609.

65. Yokoyama S, Ito Y, Ueno-Kudoh H, Shimizu H, Uchibe K, Albini S, Mitsuoka K, Miyaki S, Kiso M, Nagai A, Hikata T, Osada T, Fukuda N, Yamashita S, Harada D, Mezzano V, Kasai M, Puri PL, Hayashizaki Y, Okado H, Hashimoto $\mathrm{M}$, Asahara $\mathrm{H}$ : A systems approach reveals that the myogenesis genome network is regulated by the transcriptional repressor RP58. Dev Cell 2009, 17:836-848

66. Qi Y, Hoshino M, Wada Y, Marubuchi S, Yoshimura N, Kanazawa I, Shinomiya K, Okazawa H: PQBP-1 is expressed predominantly in the central nervous system during development. Eur J Neurosci 2005, 22:1277-1286.

67. Bäumer D, Lee S, Nicholson G, Davies JL, Parkinson NJ, Murray LM, Gillingwater TH, Ansorge $\mathrm{O}$, Davies KE, Talbot $\mathrm{K}$ : Alternative splicing events are a late feature of pathology in a mouse model of spinal muscular atrophy. PLoS Genet 2009, 5:e1000773.

68. Baguma-Nibasheka M, Kablar B: Altered retinal cell differentiation in the AP-3 delta mutant (Mocha) mouse. Int J Dev Neurosci 2009, 27:701-708.

doi:10.1186/2044-5040-2-21

Cite this article as: Farina et al:: A role for RNA post-transcriptional regulation in satellite cell activation. Skeletal Muscle 2012 2:21.

\section{Submit your next manuscript to BioMed Central and take full advantage of:}

- Convenient online submission

- Thorough peer review

- No space constraints or color figure charges

- Immediate publication on acceptance

- Inclusion in PubMed, CAS, Scopus and Google Scholar

- Research which is freely available for redistribution

Submit your manuscript at www.biomedcentral.com/submit 